Chamada Especial: Turismo e COVID-19

\title{
Como se move o turismo durante a pandemia da COVID-19?
}

\author{
How does tourism move during the COVID-19 pandemic?
}

\section{¿Cómo se mueve el turismo durante la pandemia de la COVID-19?}

\author{
Juliana Carneiro'; Thiago Allis² \\ ${ }^{1}$ Faculdade de Turismo e Hotelaria da Universidade Federal Fluminense (UFF), Niteroi, RJ, Brasil. \\ 2Escola de Artes Ciências e Humanidades, da Universidade de São Paulo (EACH-USP), São Paulo, SP, Brasil.
}

Palavras-chave:

Mobilidades turísticas; Mobilidades imaginativas; Teoria do turismo.

Keywords:

Tourism mobilities; Imaginative mobilities; Theories of tourism.

\section{Resumo}

Este artigo debate as dicotomias entre mobilidades físicas e imagéticas ocorridas na pandemia da COVID-19, considerando as restrições de fluxos de turistas contidos nas barreiras sanitárias e das comunicações turísticas que, ao mesmo tempo que alertam para a necessidade de restrição ao turismo, promovem seus atrativos na perspectiva de retomada da atividade. Para tal, fez-se uma análise de contexto a partir dos conteúdos (tipologia, representação e discurso/interpretação) presentes nos materiais difundidos pela imprensa e pelos órgãos locais das Rotas Turísticas Costa do Sol/Região dos Lagos e São Paulo/Litoral Norte. Os conteúdos empíricos são expostos como exemplos, pois a essência do trabalho está nas dinâmicas e processos das mobilidades que os caracterizam e transmutam. Os resultados corroboram o argumento que as dimensões física e imagética do turismo ilustram dois elementos principais para se (re)pensar o conceito e as práticas mobilidades turísticas. Assim, as contribuições deste trabalho se colocam em duas vertentes: primeiro, no campo teórico-metodológico das mobilidades, ao ampliar a discussão sobre turismo para além da mobilidade física de corpos, orientados pelo Paradigma das Novas Mobilidades; segundo, coloca em discussão vertentes contraditórias sobre as práticas turísticas no presente, podendo orientar a gestão da atividade em função dos desdobramentos da pandemia.

\section{Abstract}

This article discusses the dichotomies of physical and visual mobilities emerged during the COVID19 pandemic, drawing on the analysis of the tourist flows restrictions contained in health barriers and tourist communications, which, while alerting to the need to restrict tourism, promote its attractions in the perspective of a tourism recovery. For that, a context analysis was made from images (typology, representation and discourse/interpretation) circulated in press and DMOs of the Costa do Sol/Região dos Lagos and São Paulo/Litoral Norte Tourism Routes. The empirical contents are brought as examples, since the essence of this study lies in the dynamics and processes of the mobilities that characterize and transmute them. The findings corroborate the argument that physical and imaginative dimensions of tourism might become crucial to rethink the notion of tourism mobilities. Thus, the contribution of this paper is twofold: first, in the theoretical-methodological field of mobilities as it broadens the discussion on tourism beyond the physical mobility of the bodies, building upon New Mobilities Paradigm; second, it highlights contradictory dimensions on tourism practices nowadays, and may guide future management of tourism activities according to the unfolding of the pandemic. 
Palabras clave:

Movilidades turísticas; Movilidades imaginativas; Teorías del turismo.

Revisado por pares. Recebido em: 01/08/2020. Aprovado em: 27/10/2020. Editor:

Glauber Eduardo de Oliveira Santos.

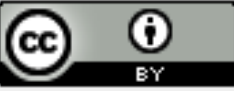

\section{Resumen}

En este artículo se analizan las dicotomías entre movilidades físicas e imaginarias que ocurrieron en la pandemia, considerando las restricciones al flujo de turistas contenidas en barreras sanitarias y comunicaciones turísticas que, al mismo tiempo que alertan sobre la necesidad de restringir el turismo, promocionan sus atractivos en la perspectiva de recuperación de la actividad. Para ello, se realizó un análisis de contexto a partir de los contenidos (tipología, representación y discurso / interpretación) presentes en los materiales difundidos por la prensa y por los organismos locales de las Rutas Turísticas Costa do Sol/Região dos Lagos y São Paulo/Litoral Norte. Los contenidos empíricos se presentan como ejemplos, porque la esencia del trabajo está en las dinámicas y procesos de las movilidades que las caracterizan y transmutan. Los resultados corroboran el argumento de que las dimensiones física e imaginaria del turismo pueden ser dos elementos principales para (re) pensar la noción de movilidad turística. Así, los aportes a este trabajo se dividen en dos vertientes: primero, en el campo teórico-metodológico de la movilidad, ampliando la discusión sobre el turismo más allá de la movilidad física de los cuerpos, guiados por el Paradigma de las Nuevas Movilidades; en segundo lugar, cuestiona aspectos contradictorios de las prácticas turísticas en la actualidad, pudiendo orientar la gestión de la actividad según las consecuencias de la pandemia.

Como citar: Carneiro, J.; Allis. T. (2021). Como se move o turismo durante a pandemia da COVID-19? Revista Brasileira de Pesquisa em Turismo, São Paulo, 15 (1), 2212. http://dx.doi.org/10.7784/rbtur.v15i1.2212

\section{INTRODUÇÃO}

A pandemia causada pelo novo coronavírus (SARS-CoV-2), decretada em março de 2020 (WHO, 2020), impôs uma brusca redução ou interrupção de fluxos turísticos, uma vez que medidas de confinamento (lockdown) foram implementadas como recursos para tentar controlar a circulação do vírus (Gössling, Scott \& Hall, 2020). Em abril de 2020, todos os destinos do mundo possuíam alguma restrição de viagem relacionadas à COVID-19, atestando que nunca as viagens internacionais foram restringidas de maneira tão extrema (UNWTO, 2020). Apenas nos seis primeiros meses de 2020, as perdas pelas companhias aéreas, por exemplo, ultrapassaram US\$ 84 bilhões (IATA, 2020).

A narrativa da desaceleração tomou conta do cotidiano. A noção quase inabalável da dinâmica dos fluxos foi repentinamente substituída pelo foco nas fricções: fronteiras fechadas, proibições de circulação, fluxos de transporte interrompidos (Baum \& Hai, 2020). Contudo, diferente do que parece, há mobilidades ocultas co-existindo com um ambiente de privação de certa normalidade móvel. Por isso, mesmo com a generalização dos confinamentos, urge indagar como as mobilidades turísticas - em que pese a inexorabilidade dos fluxos de pessoas para sua existência - se manifestam durante a pandemia.

Pensar o "turismo pós-covid" (Baba et al, 2020; Chang, Aleer \& Ramos, 2020; Haywood, 2020; Trigo, 2020 entre outros) é tarefa altamente relevante, dadas as enormes perdas das empresas vinculadas direta e indiretamente ao setor. A queda brusca no consumo e a grande demanda de cancelamentos aumenta a instabilidade financeira, colocando as empresas em situações críticas, com repercussão na oferta de empregos do setor e na saúde financeira do próprio Estado, sobretudo em localidades com maior dependência do turismo.

No entanto, a insistência em somente pensar no horizonte após a pandemia (ainda que não se tenha precisa noção do quê isso significa em termos temporais e práticos) ofusca acontecimentos e fatos que estão ocorrendo durante a pandemia, cujas análises podem subsidiar estratégias para reconstrução futura.

Para tanto, urge reconhecer e escrutinar outras dimensões do fenômeno turístico, que subjazem ou intermediam os deslocamentos físicos, buscando entender o turismo na sua complexidade e amplitude (Allis, 2016; Kunz, 2015). Ao refletirmos sobre possíveis manifestações do turismo neste contexto pandêmico, os espaços virtuais ou das mobilidades imaginativas (Elliott \& Urry, 2010; Urry, 2000) ganham maior centralidade, em contraste com a impossibilidade dos fluxos turísticos convencionais.

Nesse contexto, comunicações de destinos turísticos têm difundido imagens de maneiras pouco reconhecíveis: alerta-se para o risco de viajar, recomendando que turistas não vão ao destino, que fiquem 
em casa. Todas essas mensagens geralmente são acompanhadas de imagens da localidade, de atrativos e da população, que, de uma maneira contraditória, continuam a alimentar uma dimensão imagética e imaginativa das mobilidades turísticas.

Assumindo as mobilidades como categoria de análise (Sheller \& Urry, 2006; Freire-Medeiros, Teles \& Allis, 2018; Sheller, 2014; Cresswell, 2010; Kaufmann, 2010; Hannam et al., 2006), reconhece-se uma complexidade que também engloba, dialeticamente, as imobilidades.

Neste âmbito e do ponto de vista empírico, voltamos o olhar para as dicotomias que emergem durante a pandemia no Brasil no campo do turismo: a imposição de barreiras sanitárias diante da insistência de visitantes em manterem os fluxos turísticos, em contraste com comunicações virtuais de destinos turísticos pelas mensagens de "não venha", ainda que atreladas à imagética dos atrativos. Sem a pretensão de apresentar estudos de caso, foram elencadas e descritas situações concretas com o propósito de ilustrar e debater aspectos múltiplos das mobilidades turísticas, particularmente, acerca dos fluxos turísticos que assumem diversas formas e ritmos (pessoas, imagens, mensagens...). Isso se manifesta tanto por fricções de ordem física (barreiras nas estradas), quanto pelas intenções de modular a fluidez através da circulação de mensagens e imagens de destinos turísticos (comunicação das gestões municipais em espaços virtuais).

Em resumo, pergunta-se: como as mobilidades turísticas têm se manifestado durante a pandemia da COVID19, tendo em vista os fluxos e fricções de destinos turísticos? Neste sentido, o objetivo deste trabalho é debater as dicotomias manifestadas entre (i)mobilidades físicas e imagéticas ocorridas na pandemia da COVID-19. Nota-se que este tensionamento se mostrou mais expressivo em municípios litorâneos do Rio de Janeiro e de São Paulo, particularmente na Costa do Sol/Região dos Lagos e Litoral Norte/São Paulo. Por isso, de maneira aplicada, propõe-se analisar os fluxos e as fricções turísticas no contexto pandêmico, a partir das múltiplas dimensões de mobilidades turísticas nestas regiões, observando as medidas (formais ou não) de contenção física de fluxos (barreiras) e de comunicação turística de destinos turísticos dos litorais fluminense e paulista entre março e julho de 2020.

\section{METODOLOGIA}

As mobilidades representam uma categoria de análise que aciona um "conjunto de questões, teorias e metodologias, em vez de uma descrição totalizante ou redutora do mundo contemporâneo" (Sheller \& Urry, 2006, p. 210). Entende-se, a partir disto, as mobilidades turísticas como campo analítico que contempla e dialoga com múltiplas dimensões das mobilidades (corpos, objetos, imagens, comunicação, ideias), portanto, muito mais amplo do que o deslocamento de turistas. Esta abordagem se orienta por um "paradigma" ou "giro" das mobilidades (Freire-Medeiros, Teles \& Allis, 2018; Sheller, 2014; Cresswell, 2010; Kaufmann, 2010; Hannam et al., 2006; Sheller \& Urry, 2006), compreendidas como "fato central na vida moderna e pós-moderna", que exige novas "formas de pensar e teorizar as mobilidades" (Cresswell, 2010, p. 551).

Nesse contexto, algumas percepções - ou "sinalizadores do campo" (Baptista, 2011) - sobre o turismo na pandemia se destacaram. Tão logo a pandemia se impôs, multiplicaram-se peças de comunicação de alerta e convites futuros ao turismo no Brasil e no mundo (\#VisitLater \#TravelTomorrow).

A partir do levantamento exploratório de materiais publicitários de destinos turísticos percebeu-se um padrão de comunicação: "não venha agora, espere a pandemia acabar, mas lembre-se, estaremos aqui quando tudo isso passar", geralmente atrelado a imagens dos atrativos locais. Esta análise por si só, seria um objeto de estudo instigante. No entanto, a recorrência de notícias sobre barreiras sanitárias em diversos municípios observados foi muito marcante. E, se existem barreiras físicas com justificativa de contenção, é porque há fluxos intencionados a estes municípios.

Observou-se certa semelhança nas ações de comunicação e estratégias de bloqueios de municípios litorâneos dos estados de São Paulo e Rio de Janeiro, em geral, muito próximos das e bastante conectados a capitais e regiões metropolitanas - expostos a uma expressiva demanda turística ao longo do ano. De maneira contundente, são nestas unidades da federação que se concentram os maiores números de casos e mortes pela COVID-19, tanto pela sua intensa conexão a redes aéreas internacionais, quanto por sua magnitude e diversidade urbanas (Aguiar, 2020). 
Para esta delimitação, selecionaram-se municípios de duas Rotas Turísticas Estratégicas, preconizadas pelo Projeto Investe Turismo (Brasil, 2019): Costa do Sol/Região dos Lagos (Arraial do Cabo, Armação dos Búzios, Cabo Frio, Rio das Ostras, Saquarema, Angra dos Reis e Paraty) e São Paulo/Litoral Norte (Bertioga, Ubatuba, Caraguatatuba, Ilhabela e São Sebastião; exceto município de São Paulo) (Figura 1).

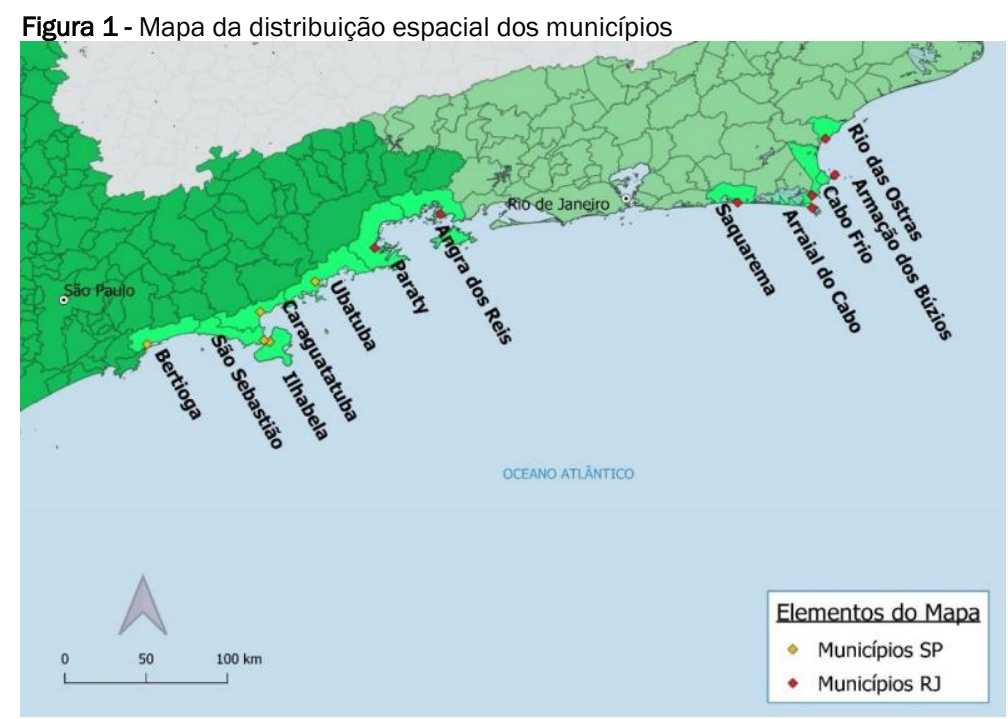

Fonte: Elaboração própria.

Este recorte põe em destaque dinâmicas da mobilidade que, talvez, não sejam exclusivas destas localidades, uma vez que há, em outros municípios brasileiros, dicotomias que sugerem (i)mobilidades turísticas igualmente instigantes.

O levantamento ocorreu a partir da data dos primeiros decretos municipais que limitavam a entrada e circulação de turistas, de março até 30 de julho 2020. Isso serviu para compor um mosaico de ilustrações, para analisar (textual e imageticamente) de que forma as mobilidades turísticas operam nas dimensões imagética e comunicativa. As comunicações turísticas foram levantadas por materiais institucionais disponíveis em meio virtual, realizados por destination marketing organizations (DMOs) em seus websites institucionais, canais do YouTube e, principalmente, contas em redes sociais (Facebook).

Cabe destacar que, ainda que os materiais institucionais levantados estejam nas redes sociais públicas das respectivas Secretarias Municipais, rostos de indivíduos e eventuais menções de nomes/perfis foram borrados com intuito de preservar a identidade dos sujeitos que figuram algumas imagens. Além disso, a utilização de imagens contidas nos meios virtuais e físicos com a finalidade exclusivamente acadêmica, de pesquisa, ou seja, não comercial, é frequente em estudos de comunicação que analisam materiais visuais, presentes em meios virtuais e/ou físicos, sobretudo, a partir da semiótica e da netnografia, como em Alves, Costa e Perinotto (2017), Seabra (2017), Mello (2015), Ferrari e Gandara (2015) e Silva e Alves (2014).

Sobre as barreiras sanitárias, buscaram-se reportagens de veículos de comunicação gerais e informes das Prefeituras e Secretarias, para mapear os mecanismos legais e administrativos empregados, bem como os embates associados à sua implementação, manutenção e recrudescimento. Os textos legais (decretos e leis) foram recuperados dos diários oficiais digitais dos municípios.

Diversos foram os desafios para a coleta de dados, dada a rapidez de divulgação das informações e mesmo dos protocolos. Mesmo assim, o levantamento sobre as barreiras sanitárias e os fluxos de visitantes (que variam substancialmente em decorrência de feriados) e as comunicações turísticas destes municípios foram realizados com o objetivo de fornecer um panorama sobre as ações públicas que subsidiarão análises sob a perspectiva das mobilidades.

A essência do trabalho está nas dinâmicas e nos processos das mobilidades que caracterizam e transmutam a realidade apreendida do território. Por isso, diferente de um trabalho detalhado sobre a definição de políticas públicas em torno destas questões, almeja-se entender como estas situações extremas e 
extraordinárias podem apontar (novas) trilhas de pesquisas sobre mobilidades e turismo. A noção de "constelação" de fenômenos móveis (Cresswell, 2010) orienta e instrumentaliza a pesquisa, a partir de seis questões sobre as mobilidades de pessoas e coisas: por que (motivo)? Quão rápido (velocidade)? Em qual ritmo? Por quais rotas (trajetórias)? Quais as experiências? E quando e como são interrompidas (fricções)? Neste estudo, ritmo e fricção serão especialmente relevantes.

A complexidade latente do turismo (no contexto pandêmico) pressupõe processos de reflexões dialéticos pautados no pensamento crítico, estando atrelados diretamente com a mobilidade como categoria de análise (Sheller \& Urry, 2006) - sem negligenciar seu oposto (a imobilidade). Estas, por sua vez, são percebidas pela possibilidade diferencial de acionamento das redes e recursos que possibilitam a mobilidade de indivíduos no espaço, física e simbolicamente (Sheller, 2018b) em diferentes dimensões (Figura 2).

Figura 2 - Dimensões de análise

Mobilidade virtual/imaginativa: Representação do espaço na imagem
Imobilidade física: Barreiras sanitárias e quarentena

\section{Mobilidades desiguais}

Mobilidades

flexíveis de alguns turistas
$\mathrm{X}$

$\mathrm{x}$

de moradores e potenciais turistas menos privilegiados

Fonte: Elaboração própria (2020)

Somada a isso, a perspectiva acerca das comunicações turísticas (Mello, 2015; Baldissera, 2010) orienta o estudo sobre a construção e movimentação de imagens através de imaginários (Elliott \& Urry, 2010; Urry, 2000). Portanto, a análise das imagens (fotografias e vídeos) permite entender como o fenômeno das mobilidades turísticas se manifesta também nas distintas comunicações turísticas durante a pandemia, numa dimensão imagética (e não cinética, ou seja, a de corpos em movimento) (Figura 3).

Figura 3 - Elementos de leitura das comunicações turísticas

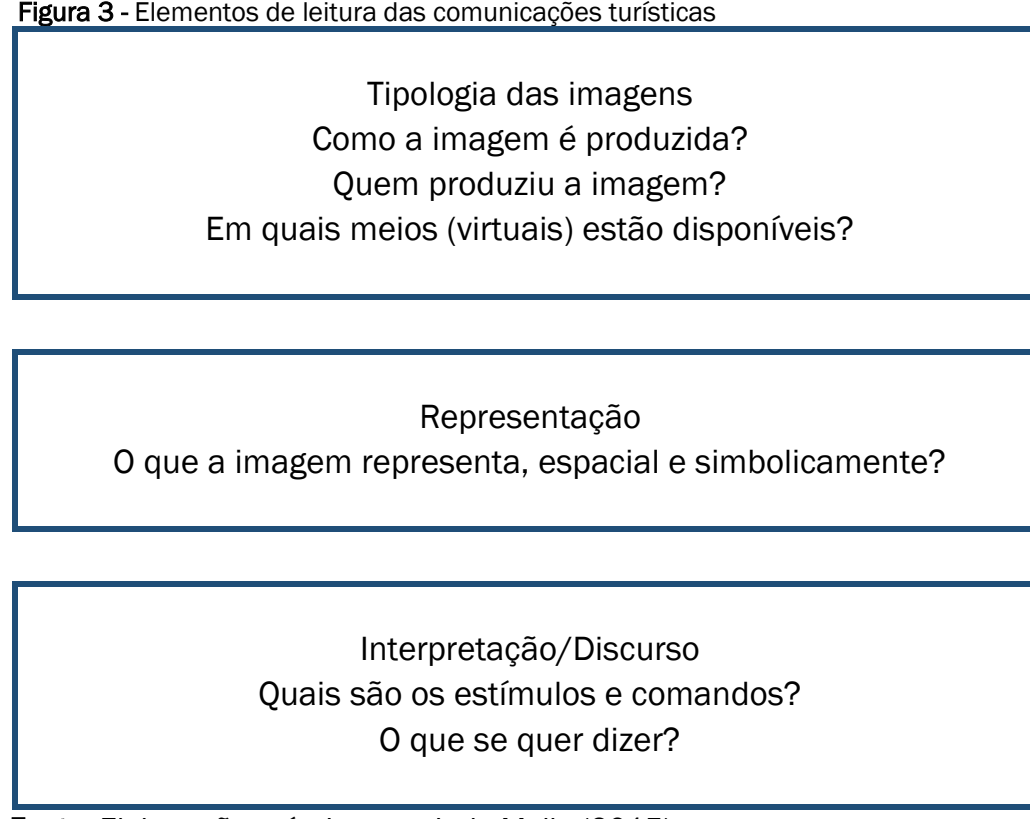

Fonte: Elaboração própria a partir de Mello (2015) 
A revisão de literatura foi realizada através de diferentes combinações dos seguintes descritores: "pandemia, COVID-19, turismo, viagem, doença, vírus e mobilidade", em inglês e português, nas bases de dados Scopus (27 resultados) e Google Acadêmico (85 resultados), até 30 de julho de 2020. Não foram estabelecidos filtros temporais, nem de áreas temáticas - justamente para poder identificar a dispersão do tema na literatura pesquisada. Deste resultado, foram excluídos trabalhos que não tratavam sobre mobilidade e contextos pandêmicos ou de emergências-sanitárias, resultando em 23 publicações. Não era a intenção produzir uma revisão de literatura exaustiva, nem uma análise bibliométrica completa, especialmente porque as publicações sobre a temática estão em crescimento, não sendo possível descrever o comportamento das publicações com exatidão. Os direcionamentos para revisão da literatura permitiram observar publicações que, embora nem sempre ancoradas nos preceitos das mobilidades, abordam aspectos que possam contribuir para a consolidação das mobilidades turísticas como campo de estudo.

\section{DOENÇAS E MOBILIDADES TURÍSTICAS}

\subsection{Mobilidades como novo enfoque para os estudos do turismo}

No contraste com o capitalismo fordista do século XX, atualmente, os modos de (re)produções espaciais devem ser compreendidos por uma perspectiva mais ampla e complexa, em que a cotidianidade, através dos lazeres e da cultura, desempenha papéis marcantes (Lefebvre, 2008). Como decorrência, vivenciamos - não sem conflitos - múltiplas modalidades de territórios, de forma simultânea (mobilidade "virtual") ou sucessiva (mobilidade física), surgindo assim, uma nova "experiência espacial integrada": a experiência da multiterritorialidade (Haesbaert, 2014).

Como caixa de ressonância para narrativas pandêmicas, o "giro das mobilidades" representa um robusto arcabouço para expandir (e questionar) o pressuposto de que "todo o mundo parece estar em constante movimento". Com novos entendimentos ou paradigmas sobre as mobilidades, constitui-se um campo de análise - muito mais complexo do que um objeto poderia supor (Sheller \& Urry, 2006; Sheller, 2018a), indicando um profícuo caminho para o estudo das mobilidades turísticas (Figura 4).

Figura 4 - Componentes do Paradigma das Novas Mobilidades

Relações móveis complexas e
multiescalares, em que fluxos e
circulações são definidas por
amarrações temporárias (em vez
de epistemologias sedentárias e
nacionalismo metodológico)

Interligações entre mobilidades físicas, virtuais, comunicativas e imaginativas (pessoas, objetos, informações, capital e recursos assim como as imobilidades

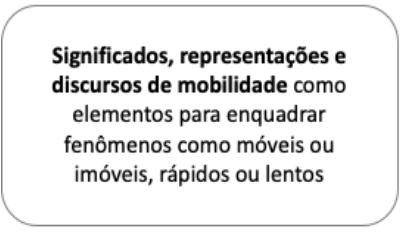

\section{Paradigma da Novas \\ Mobilidades}

(Sheller \& Urry, 2006; Sheller, 2018b)

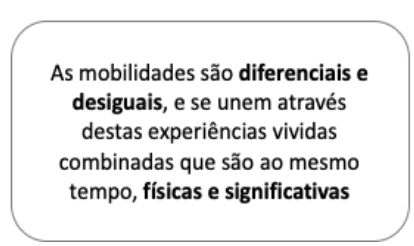

Fonte: Adaptado de Sheller e Urry (2006) e Sheller (2018b)

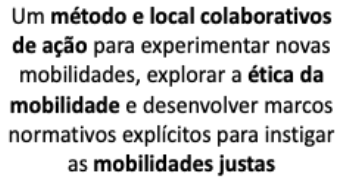

Um método e local colaborativos de ação para experimentar novas mobilidades, explorar a ética da mobilidade e desenvolver marcos normativos explícitos para instigar as mobilidades justas

Considerando que as mobilidades também incluem movimentos de imagens e informações em diferentes escalas, formatos e alcances (Sheller \& Urry, 2006), as viagens imaginativas proporcionadas pelas imagens dos lugares e as viagens virtuais ultrapassam distâncias geográficas e sociais, no bojo de múltiplos sistemas e regimes de mobilidade (Elliott \& Urry, 2010). 
No âmbito da comunicação turística, indivíduos, grupos e instituições agem nos processos de representação do espaço, articulando representações simbólicas para dizer e compreender algo (Baldissera, 2010), desdobrando possibilidades para se viajar simbolicamente (Elliott \& Urry, 2010).

De maneira mais específica, "mobilidades turísticas envolvem combinações complexas de movimento e pausa, realidades e fantasias, diversão e trabalho" (Sheller \& Urry, 2004, p. 1). Assim, um par de sentidos ajudam a entender a multi-dimensionalidade das mobilidades turísticas: de um lado, uma cadeia de produção de espaços para fruições turísticas (places to play); de outro, e de forma quase metafórica, os próprios lugares viajam e estruturam culturas turísticas mundo afora (places in play). Ambas entradas informam sobre e moldam o turismo, impulsionando "a criação e invenção de destinos turísticos" (p. 1).

De fato, seria desnecessário (talvez mesmo impossível) distinguir "pessoas" e "lugares" neste amálgama das mobilidades turísticas, já que "os lugares (...) não são tão fixos, mas estão envolvidos em redes complexas", que produzem determinadas performances (Hannam, Butler \& Paris, 2014, p. 173). Com efeito, o uso das tecnologias reforçou a hibridização do espaço, pois os indivíduos estão produzindo novos lugares e experiências espaciais. Cada vez mais, sujeitos móveis estão levando consigo dispositivos portáteis - ou miniaturizados (Elliot \& Urry, 2010) - em suas jornadas, alternando entre a presença corporal e virtual. A emergência do ciberespaço reconfigurou e mobilizou o próprio conceito de espaço, onde os espaços virtuais são desenhados com base no interesse humano e não na proximidade física, permitindo socializações instantâneas, bem como outras formas de co-presença - para além do contato físico (Hannam et al., 2014).

Da mesma forma que imagens e informações viajam para divulgação e promoção de um destino, uma localidade pode sofrer com o inverso, como em Hong Kong em decorrência da epidemia da SARS, de 2003, quando a cidade perdeu o posto de "City of Life" para lugar de medo (Sung \& So, 2004). Neste exemplo, a movimentação de imagens e informações produziu menos deslocamentos, uma vez que a esta crise sanitária tirou, momentaneamente, a cidade do "palco global" (Sheller \& Urry, 2004). Neste contexto, fica claro que a comunicação turística (objetivada ou espontânea) pode ser um fator de mácula da imagem e sucesso de destinos turísticos (Baldissera, 2010).

Por fim, cabe apontar que a imobilização pode se manifestar nas dimensões simbólicas e físicas do território - a exemplo de novos controles de acesso a porções do território. Normalmente, os espaços são desigualmente porosos para distintos grupos e, no contexto pandêmico, certos instrumentos de poder são potencializados: desde o limiar entre o privilégio do auto-confinamento (que opõe a segurança da casa ao risco da rua), até debates que questionam protocolos e práticas de proteção coletiva (minguando sociabilidades - as viagens incluídas - através de restrições de ordem operacional e espacial).

Nesse sentido, é imperativo reforçar que as mobilidades não se manifestam iguais para todos e todas: diversas vivências (i)móveis se apresentam, em primeiro lugar, nas diferenças de acesso e na conectividade parcial (física, simbólica, virtual). Referem-se também aos movimentos com maior ou menor grau de facilidade, conforto, flexibilidade e segurança - a depender das fricções a que indivíduos estejam expostos.

\subsection{Breve panorama da literatura recente}

O mundo sofreu uma série de grandes crises sanitárias nos últimos 40 anos, porém nenhuma teve implicações semelhantes para o mundo como a pandemia da COVID-19 (Gössling, et al., 2020). Até 2019, a maior parte da literatura sobre turismo e surtos epidemiológicos tratava do HIV, Ebola, SARS, com claro destaque para a pandemia do H1N1 ("gripe suína"), incluindo estudos da disseminação de doenças pela mobilidade humana, especialmente os viajantes (Merler et al., 2011; Belik et al., 2011; Meloni et al., 2011; Bajardi et al., 2011), sobre transportes aéreos (Epstein et al., 2007; Martin \& Boland; 2018) e arranjos institucionais internacionais relativos à biossegurança (Hall, 2011).

Um aspecto importante desta (recente) literatura é a crítica ao papel do turismo/turista como elemento dispersor das enfermidades, COVID-19 em particular (laquinto, 2020; Sánchez, 2020). Mudanças no movimento populacional, como migrações, viagens de negócios e turismo em um mundo muito mais globalizado, fizeram com que este vírus se espalhasse de forma diferente (Shi et al., 2020). Outros trabalhos tratam dos efeitos e cenários para o setor aéreo produzidos pela imobilidade forçada (lacus et al., 2020; 
Oliveira Neto et al., 2020) e, em vertente mais otimista, sobre o papel dos cruzeiros para atenuar as desigualdades locais no pós-pandemia (Renaud, 2020).

Grosso modo, quando se fala em turismo pós-pandemia, os olhares dividem-se entre uma expectativa de recuperação (recovery) dos níveis de turismo anteriores, tão logo protocolos médico-sanitárias sejam implementados, e outra que busca uma reforma (reform), oportunidade de repensar seus princípios e éticas (Gössling et al, 2020; Hall, Scott \& Gössling , 2020; Higgins-Desbiolles, 2020a; 2020b; Jamal \& Budke, 2020). Ademais, expectativas com o chamado "turismo de proximidade" (loannides \& Gyimóthy, 2020) e valorização de práticas tradicionais em um regime de mobilidades mais justas (Sheller, 2020).

Ainda que as mobilidades não apareçam explicitamente como categorias de análise, estudos abrem discussões sobre o direito de se mover no contexto pandêmico, considerando restrições de deslocamentos, barreiras físicas e fechamento de fronteiras (Tremblay-Huet, 2020; Baum \& Hai, 2020).

Alguns trabalhos estudam a relação das comunicações com turismo durante a pandemia, tratando das percepções de turistas e discriminação racial (Yu et al., 2020), bem como seus efeitos na saúde mental de turistas chineses vítimas de ataques racistas (Zheng et al., 2020). Ainda nesta vertente, Depoux et al. (2020) fazem um paralelo metafórico entre virologia e viralidade - em que a disseminação de informações e imagens distorcidas reforçam o racismo e outras intolerâncias. Tais narrativas xenófobas inserem-se em um "jogo da culpa geopolítica", na qual, simbolicamente participam "os imaginários turísticos do lugar". Com um desenho de "futuro incerto da (i)mobilidade global", a retomada do turismo dependeria de "autocuidado coletivo e bom gerenciamento da ansiedade geopolítica" (Mostafanezhad et al., 2020, p. 185).

\section{4 (I)MOBILIDADES TURÍSTICAS: TURISMO PANDÊMICO?}

\subsection{Barreiras sanitárias: fricções ao escapismo da quarentena}

Observando em retrospectiva, nota-se um padrão recorrente nas medidas de contenção promovidas por diferentes países com respostas à tentativa de diminuir/desacelerar a dispersão do vírus. Todas elas, em menor ou maior grau, miram no controle da mobilidade do corpo-território, sendo este, nunca dissociado do domínio e apropriação territorial do seu entorno (Haesbaert, 2020).

Nos municípios do litoral fluminense e paulista, os primeiros decretos municipais sobre as barreiras ou bloqueios sanitários datam da segunda e terceira semanas de março, com sucessivas atualizações e ajustes. Estas foram medidas que, para além das providências gerais de controle de circulação e aglomeração, buscavam conter particularmente fluxos de natureza turística.

Os feriados da Semana Santa (10 a 12 de abril de 2020), Tiradentes (21 de abril de 2020) e São Jorge (23 de abril de 2020), no Rio de Janeiro, e o assim chamado "mega-feriado" em maio em São Paulo (entre 20 e 24 de maio de 2020) - que serviria para aumentar taxas de isolamento social - foram destaques em reportagens, surpreendendo pela magnitude dos fluxos de pessoas em viagens de caráter turístico, quando, por regra, ambos os estados impunham medidas de isolamento social.

Assim, diferente do que se esperaria em situações normais, a reação de municípios turísticos foi imediata. Com diferentes intensidades e organização, municípios litorâneos de São Paulo e Rio de Janeiro empregaram procedimentos de contenção, orientação, checagem, higienização e conscientização de turistas e moradores, seja no acesso aos municípios, ou no uso de espaços públicos de interesse turísticos (principalmente praias). Em alguns casos, prefeitos assinaram decretos específicos, incluindo diferentes níveis de restrição de pessoas não residentes ou que não trabalhavam no município; em outros, o Ministério Público interveio no sentido de instar municípios a empregarem medidas de controle e monitoramento desses fluxos.

Desde as primeiras medidas legais, diversos municípios enrijeceram as fiscalizações e contenções, por causa da proximidade de feriados e da intensa procura pelas localidades nos meses anteriores. Em geral, os primeiros bloqueios tiveram como argumento a prevenção na disseminação do vírus, o aumento de casos no município, repercutindo, por vezes, recomendações da Agência Nacional de Vigilância Sanitária (ANVISA) ou da Organização Mundial da Saúde (OMS) (Quadro 1). 
Quadro 1 - Decretos municipais - SP e RJ

\begin{tabular}{|c|c|c|}
\hline Municípios & Medidas legais & Principais aspectos \\
\hline Angra dos Reis (RJ) & $\begin{array}{l}\text { Decreto } 11.596 \\
\text { (17 de março de 2020) }\end{array}$ & $\begin{array}{l}\text { Proibição de acesso e permanência de turistas às } \\
\text { praias e ilhas da Baía de Ilha Grande }\end{array}$ \\
\hline Armação dos Búzios (RJ) & $\begin{array}{l}\text { Decreto } 1.366 \\
\text { (21 de março de 2020) }\end{array}$ & Proibição de acesso de não moradores \\
\hline Arraial do Cabo (RJ) & $\begin{array}{l}\text { Decreto } 3.054 \\
\text { (18 de março de 2020) }\end{array}$ & $\begin{array}{l}\text { Suspensão ou restrição de passeios turísticos, aces- } \\
\text { sos de transportes turísticos ao município e aluguel } \\
\text { por temporada }\end{array}$ \\
\hline Bertioga (SP) & $\begin{array}{l}\text { Decreto } 3.316 \text { e } 3.362 \\
\text { (16 e } 24 \text { de abril de } 2020)\end{array}$ & $\begin{array}{l}\text { Suspensão das autorizações para entrada de veículo } \\
\text { de turismo e a controle estratégico nos acessos da } \\
\text { cidade. }\end{array}$ \\
\hline Cabo Frio (RJ) & $\begin{array}{l}\text { Decreto } 6.205 \text { e } 6.229 \\
\text { (16 de março e } 9 \text { de abril de 2020) }\end{array}$ & $\begin{array}{l}\text { Barreira sanitária, restrição de acesso a moradores, } \\
\text { fechamento do comércio e controle de acesso a es- } \\
\text { paços públicos }\end{array}$ \\
\hline Caraguatatuba (SP) & $\begin{array}{l}\text { Decreto } 1.231 \\
\text { (16 de março de 2020). }\end{array}$ & $\begin{array}{l}\text { Barreira sanitária no acesso à cidade para informar e } \\
\text { conscientizar transeuntes, suspensão das autoriza- } \\
\text { ções para entrada de veículo de turismo }\end{array}$ \\
\hline Ilhabela (SP) & $\begin{array}{l}\text { Decreto } 8.031 \\
\text { (20 de março de 2020) }\end{array}$ & $\begin{array}{l}\text { Definição de critérios e sistema de autorização para } \\
\text { acesso de pessoas e automóveis pela balsa }\end{array}$ \\
\hline Paraty (RJ) & $\begin{array}{l}\text { Decreto } 27 \\
\text { (22 de março de 2020) }\end{array}$ & $\begin{array}{l}\text { Controle e fiscalização de carros e pessoas sem resi- } \\
\text { dência no município e suspensão de autorização de } \\
\text { contratos de aluguel temporário }\end{array}$ \\
\hline Rio das Ostras (RJ) & $\begin{array}{l}\text { Decreto } 2.507 \\
\text { ( } 8 \text { de abril de } 2020)\end{array}$ & $\begin{array}{l}\text { Implantação de quatro barreiras sanitárias para ori- } \\
\text { entações e checagem. }\end{array}$ \\
\hline Saquarema (RJ) & $\begin{array}{l}\text { Decreto } 1.994 \\
\text { (2 de abril de } 2020)\end{array}$ & $\begin{array}{l}\text { Proibição de entrada de turistas, veranistas e visitan- } \\
\text { tes através de transporte público coletivo, de turismo, } \\
\text { táxis, transporte por aplicativos e veículos particula- } \\
\text { res. }\end{array}$ \\
\hline São Sebastião (SP) & $\begin{array}{l}\text { Decreto } 7.712 \text { e } 7.713 \\
\text { (19 e } 20 \text { de março de } 2020 \text { ) }\end{array}$ & $\begin{array}{l}\text { Restrição a atrativos turísticos, circulação de trans- } \\
\text { portes turísticos de um dia, acesso de veículos de } \\
\text { transporte coletivo de passageiros interestaduais }\end{array}$ \\
\hline Ubatuba (SP) & $\begin{array}{l}\text { Decreto } 7.309 \\
\text { (17 de março de 2020) }\end{array}$ & $\begin{array}{l}\text { Suspensão ou restrição de passeios turísticos, funci- } \\
\text { onamento de bares e restaurantes e atividades que } \\
\text { gerem aglomerações, acessos de transportes turísti- } \\
\text { cos ao município e implantação de barreiras sanitá- } \\
\text { rias }\end{array}$ \\
\hline
\end{tabular}

Fonte: Elaboração própria com base nos primeiros decretos municipais.

Ainda em abril, em decorrência da Semana Santa, Cabo Frio já havia registrado o bloqueio de $30 \%$ dos carros que se destinavam ao município. Cerca de 200 dos 700 carros abordados por dia nas barreiras sanitárias foram impedidos de entrar no município por conduzir pessoas que não moravam ou trabalhavam na cidade. Já no feriado do Dia de Trabalho, 2 mil veículos, dos 20 mil abordados, foram impedidos de entrar (Folha dos Lagos, 2020).

Em junho de 2020, Armação dos Búzios emitiu um novo decreto, alterando as disposições iniciais sobre barreiras sanitárias. A mudança consistiu no aumento da rigidez na comprovação de residência do indivíduo que chegava à cidade. Isso porque muitos proprietários de imóveis disponibilizavam os seus comprovantes de residências aos grupos que alugavam sua casa por um período, gerando uma interpretação fluida sobre a origem dos indivíduos (O São Gonçalo, 2020).

Essa facilitação dos proprietários também foi observada em Arraial do Cabo, o que levou o reforço da barreira sanitária em 10 de junho de 2020. A Secretaria de Segurança Pública e o Procon passaram a receber 
denúncias que empresários e donos de casas de aluguel de temporada estariam colaborando para a entrada de turistas na cidade (Prefeitura de Arraial do Cabo, 2020).

Durante a restrição de acesso a llhabela, os efeitos dos contornos realizados por alguns grupos foram nítidos. Segundo moradores, não houve a devida fiscalização de entregadores, barcos e de helicópteros. Há relatos do aumento de circulação no período do feriado do Dia do Trabalho e, semanas depois, o número de casos de COVID-19 aumentou oito vezes, consolidando a transmissão comunitária no território (Garcia, 2020).

Em contrapartida, em Paraty, desde o início da pandemia, moradores locais se organizaram para garantir seus isolamentos, com a criação de barreira sanitária nos bairros. A comunidade elaborou um manual de orientações com procedimentos de segurança motivados pela grande quantidade de carros que entravam na cidade durante feriados (Vai Paraty, 2020).

Após o decreto municipal de Angra dos Reis que limitava o acesso a llha Grande, pescadores realizam um protesto e bloqueiam desembarque de barca na ilha. Os barqueiros colocam telha com cabos de aço com suas embarcações para isolar o cais da Vila do Abraão e evitar que atracassem no local (Cristine, 2020). Em São Sebastião, moradores "hostilizaram" turistas que, mesmo com o decreto de proibição do acesso aos diversos atrativos, permaneciam na praia (Veja, 2020).

Os exemplos descritos demonstram como alguns turistas acionam suas redes de influência mais facilmente que outros: mesmo que instrumentos normativos imponham barreiras, turistas e moradores (re)produzem seus territórios-rede plenamente, apesar da dimensão institucional das regras. As segundas residências (fenômeno historicamente difundido nas regiões em estudo) são, aparentemente, o reforço e facilitador destes fluxos.

Há, de um lado, turistas tentando operar a identidade de moradores ao se deslocarem "ao longo de circuitos que canalizam fluxos" (Haesbaert, 2020, p. 2), pelos sistemas viários e das automobilidades; de outro, demais grupos - exercendo sua fixidez de moradores - exercem pressão em sentido contrário, buscando aumentar as fricções nos fluxos que demandam o litoral, seja de maneira independente (moradores erguendo barreiras informais), seja institucionalizada (decretos municipais emanados do Executivo local ou ações do Judiciário em prol do interesse público).

Parece que o sentimento de ansiedade sobre a mobilidade (Cresswell, 2006) se escancara nesses deslocamentos intransigentes, possibilitados especialmente pela autonomia conferida pelo carro (Hannam et al., 2014). 0 automóvel anuncia a opção de se mover ao permitir estar em um local aparentemente protegido, situado entre o restrito (privado) e a possibilidade de acesso ao público (espaços amplos e supostamente mais salubres, distantes das metrópoles empestadas). 0 automóvel - que carrega ocupantes de identidades móveis e mutantes - se contrapõe aos ônibus turísticos, explicitamente proibidos em decretos de certos municípios, repelidos sumariamente, não sendo tão fácil ao veículo e aos ocupantes contornarem as regras.

Que tipo de turismo representam esses deslocamentos controversos? Ficar "morando" na sua casa de praia por algumas semanas exime um visitante da condição de turista? Por outro lado, um comprovante de residência que o permita entrar na cidade garante o status de morador? A despeito de (re)conceituações liminares, identidades híbridas definem mobilidades estratégicas para que certos grupos transitem entre territórios que Ihes convenham - sendo que, nestes casos, ocultar sua condição de turista (ou, no mínimo, de não morador) é recurso crucial.

A mobilidade flexível dos visitantes é contrastada pela imobilidade de outros, como, por exemplo, moradores que não têm, em geral, condição de deixar estas localidades, ou turistas em potencial que dependeriam de hospedagem temporária ou de veículos coletivos (estes mais facilmente repelidos nas barreiras). 0 privilégio de um grupo que aciona as redes móveis quando desejam se acentua em momentos extremos.

A mobilidade, como instrumento de poder, não só no que tange a desigualdade no acesso a diferentes velocidades e tipos de deslocamentos, como também sobre como o deslocamento rápido de uns, afeta os tipos de alcance, ritmos e acesso a recursos de outros (Haesbaert, 2014). Essa "mobilidade desigual" se manifesta pelo acesso diferencial ou conectividade parcial, pelos meios de modos de movimento que 
possuem maior ou menor grau de facilidade, conforto, flexibilidade e segurança, pelas formas da cidade e gerenciamentos de contraditórios regimes de mobilidade (Sheller, 2018b).

Em contraponto, há ações de resistência dos moradores, acentuando o encontro entre a ação institucional (decretos municipais) e a comunicação não-oficial (articulação dos moradores) acerca das contenções dos fluxos de turistas - sejam nas ruas e praias e literalmente nas águas, como em Ilha Grande.

Restrições de entrada e saída de turistas (ou seja, não residentes) são complexas e exigem do Estado medidas de cautela e fiscalização. De qualquer forma, é essencial reconhecer que "mover-se fisicamente ou virtualmente entre lugares pode ser uma fonte de status e poder" (Sheller \& Urry, 2006), que assistem de maneira desigual aos distintos grupos.

\subsection{Comunicações turísticas: algum turismo segue fluindo nas redes}

A grande quantidade de imagens utilizadas nas comunicações turísticas confirma que este recurso imagético se tornou o principal suporte estratégico para os enunciadores midiáticos. Não só com objetivo de materializar os destinos turísticos, mas também manterem e (re)elaborarem imaginários (Mello, 2015).

Os vídeos também tiveram destaque nas comunicações turísticas durante a pandemia. Neste contexto, o vídeo, híbrido por natureza, tem a capacidade de recodificar experiências contemporâneas e transitar no âmbito das mais diversas expressões, produzindo um alargamento de sentidos, circunscrito em ambientes e fluxos contínuos de informação (Mello, 2004).

Em ambos os formatos há uma combinação de comunicação escrita e verbal: publicações de imagens com legendas e os vídeos narrados, em geral, incitam o receptor (leitor/ouvinte). A variedade também foi percebida sobre as plataformas utilizadas: Facebook, YouTube e websites de órgãos oficiais do turismo das localidades.

O espaço representado pelas imagens e mensagens é comunicado durante a pandemia por narrativas inéditas. A mensagem narrada em vídeo de Ilhabela sintetiza a conduta dos destinos, com destaque para as contradições entre a necessidade de interrupção momentânea de fluxos turísticos e o desejo de breve retorno:

\footnotetext{
Todo mundo ama Ilhabela. (...) Gostamos de te levar para passear, se divertir, comer de tudo um pouco ou só passear na Vila. Mas, infelizmente, tivemos que nos fechar. Logo a gente, que gosta tanto de te convidar para conhecer a nossa ilha. Agora estamos com o coração apertado de falar isso para vocês, mas não venham para llhabela agora. Fiquem em casa! 0 Brasil todo cabe dentro de Ilhabela, mas somos pequenos e precisamos nos fechar para o bem de todos. É hora de proteger vidas. As nossas, de quem vive aqui e também a sua, que gosta tanto de vir para cá. Vamos continuar aqui, te mostrando tudo o que a gente tem de bom e quando tudo isso passar, estaremos prontos para te receber, com toda segurança e carinho que você merece. Até daqui a pouco. \#ATÉDAQUIAPOUCO (Ilhabela, 2020. Grifo nosso).
}

Ao abordar o contexto pandêmico, difundem-se pedidos para que não se viaje para Ilhabela, com justificativas comunicadas de maneira afetuosa. A despedida remete a um futuro próximo, em que todos estarão juntos novamente.

No vídeo institucional de Saquarema, um primeiro ponto que chama atenção na narração é o cuidado com a comunidade local que, ao mesmo tempo, se torna a emissora da mensagem: a necessidade de se fechar para cuidar dos moradores, ainda que seja necessário "sacrificar" a operação turística. Novamente, há contraposição entre a transmissão em massa de imagens dos atrativos turísticos com a narração de "não viaje para cá agora". Noutra parte do vídeo, representações do imaginário turístico destacam um "clássico" turista tirando foto, como reforço para que a cultura da viagem não arrefeça durante o isolamento (Figura 5). 
Figura 5 - Vídeo institucional de Saquarema

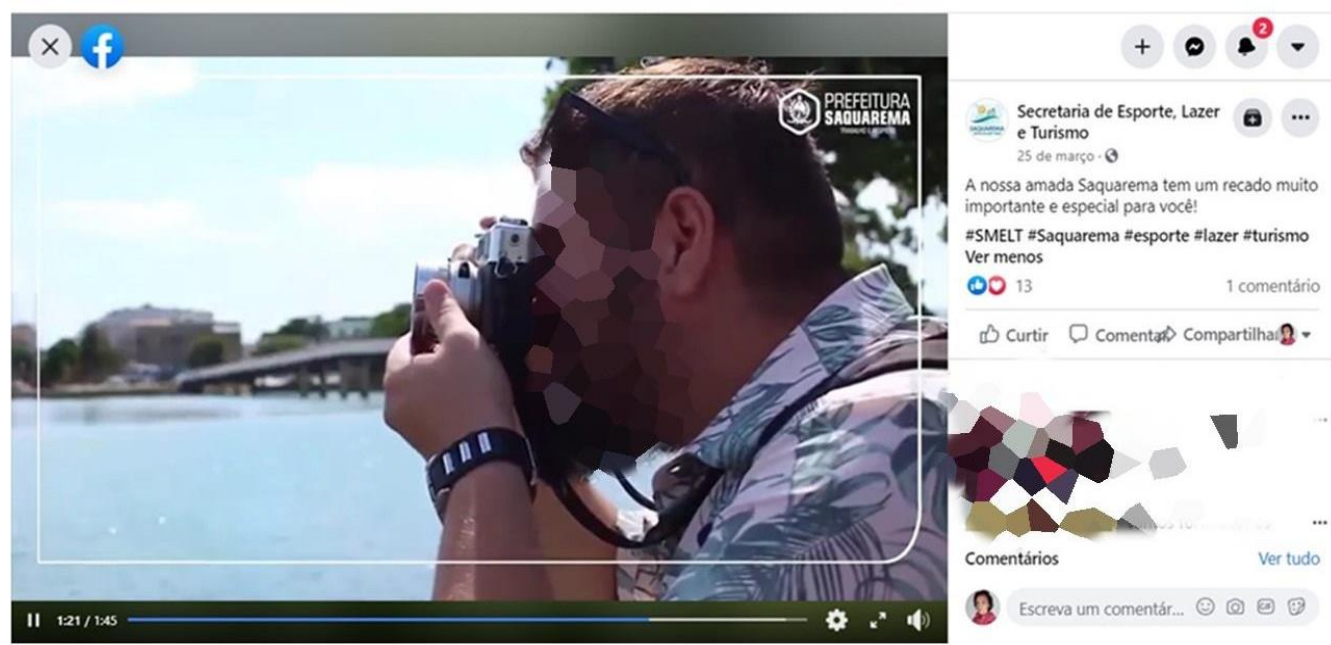

Fonte: Secretaria de Esporte, Lazer e Turismo de Saquarema. Facebook. Março de 2020.

Em contraste ao protagonismo da população local em algumas peças, poucos municípios se dedicaram ao trabalhador do turismo, como Arraial do Cabo que, ao reverenciar os guias de turismo, também fornece orientações sobre a contratação do profissional (Figura 6). 0 que não deixa de ser mais uma das contradições: enquanto estimula a contratação deste profissional, a publicação traz uma \#fiqueemcasa. Este é um exemplo de como as comunicações turísticas durante a pandemia também se dedicam a mobilizar informações visando uma operação turística regular - ainda que, por ora, se supõe estar interrompida.

Figura 6 - Publicação da Secretaria de Turismo de Arraial do Cabo
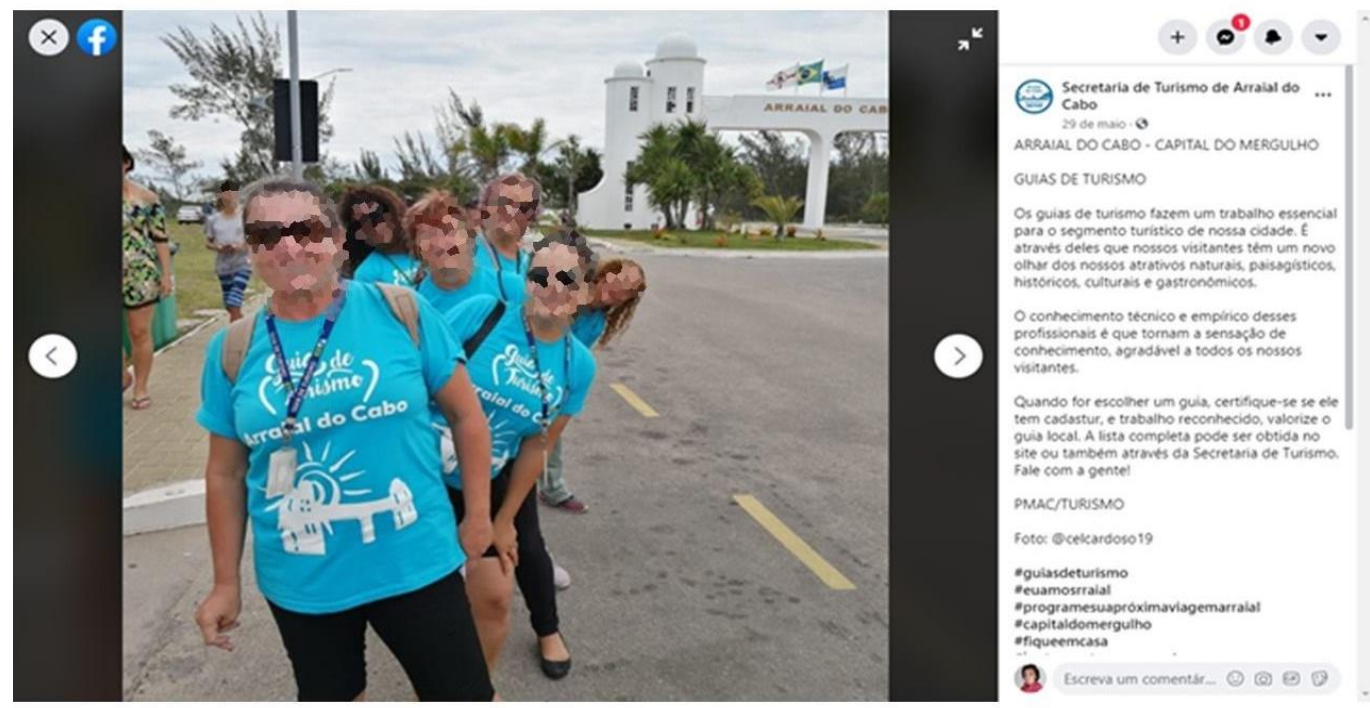

Fonte: Secretaria de Turismo de Arraial do Cabo. Facebook. Maio de 2020.

A cultura local está muito presente nas comunicações de Paraty, ao reforçar o título de Patrimônio Mundial da UNESCO. Um vídeo em inglês reproduz um discurso similar ao de llhabela - reforçando o caráter temporário da pandemia (it will pass), bastante recorrente nas comunicações de DMOs ao redor do mundo (Figura 7). 
Figura 7 - Parte do vídeo institucional de Paraty

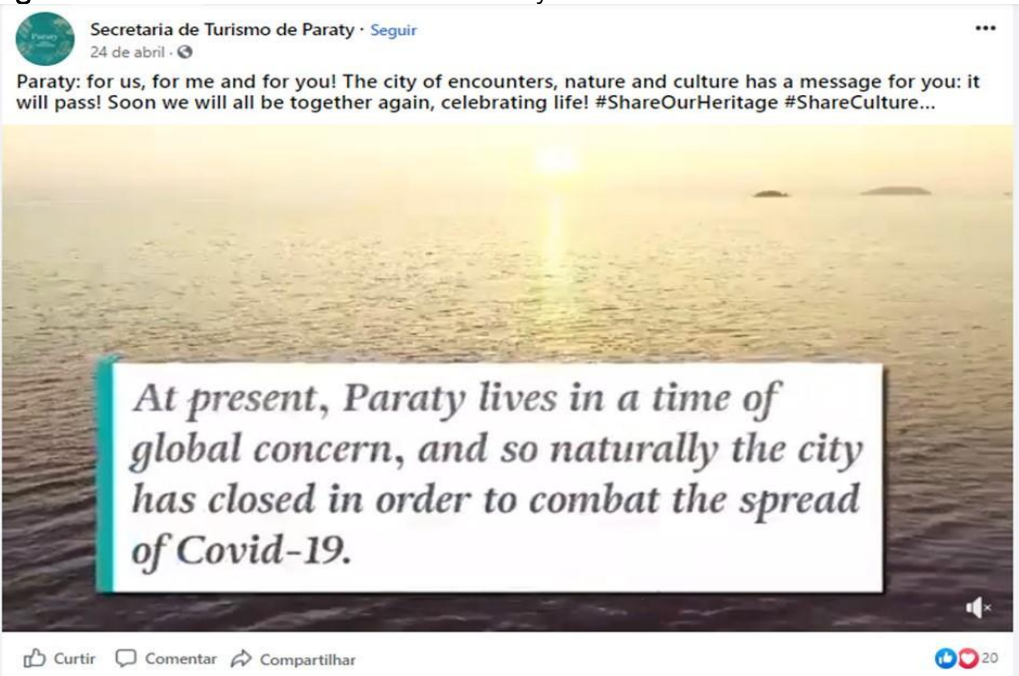

Fonte: Secretaria de Turismo de Paraty. Facebook. Abril de 2020.

Armação dos Búzios foi o município que mais atrelou sua comunicação à campanha "Não cancele, remarque", perspectiva que se aproxima do mercado turístico e a situação financeira dos destinos e empresas turísticas. Em conjunto, também promove imagens do destino e a mensagem de "venha depois" (Figura 8). Esta tentativa de manter a perspectiva de consumo, de maneira indireta, também cria uma sensação de continuidade, ainda que os fluxos turísticos estivessem interrompidos.
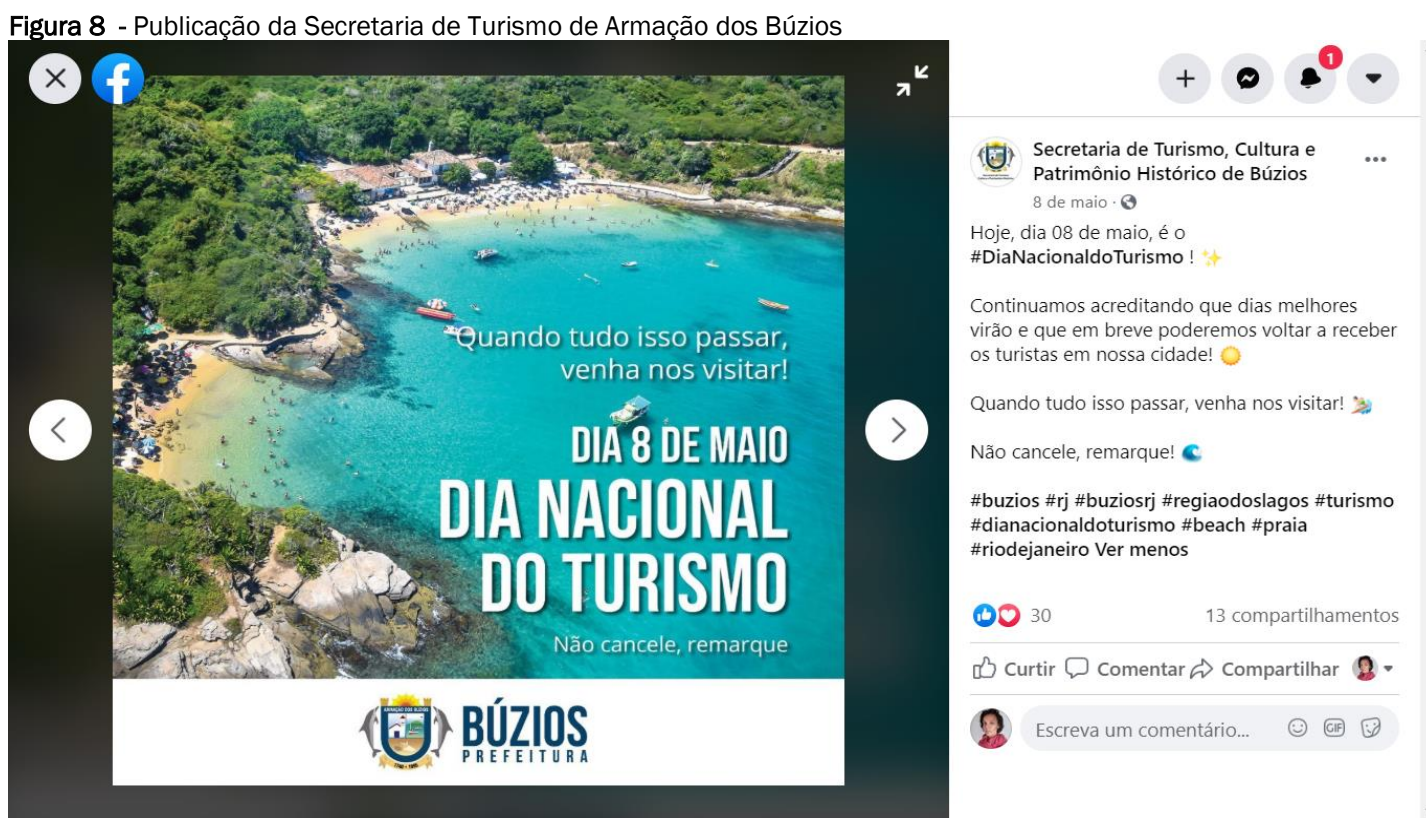

Fonte: Secretaria de Turismo, Cultura e Patrimônio Histórico de Armação dos Búzios. Facebook. Maio de 2020.

Não foram percebidas interações sobre a pandemia e o turismo em Rio das Ostras, Ubatuba, Bertioga e Caraguatatuba. Rio das Ostras, ainda que não tenha páginas ativas nas redes sociais, dispõe de um site institucional que permite uma "viagem virtual", ao convidar o leitor (ou turistas?) a "experimentar seus pontos turísticos". Porém, ao não realizar alusão à pandemia, fica implícita uma aparente normalidade (Figura 9). 
Figura 9 - Website da Secretaria de Turismo de Rio das Ostras PÁGINA INICIAL ACIDADE VERVIÇOS

NotícIAs

FALE CONOSCO

PESQUISAR

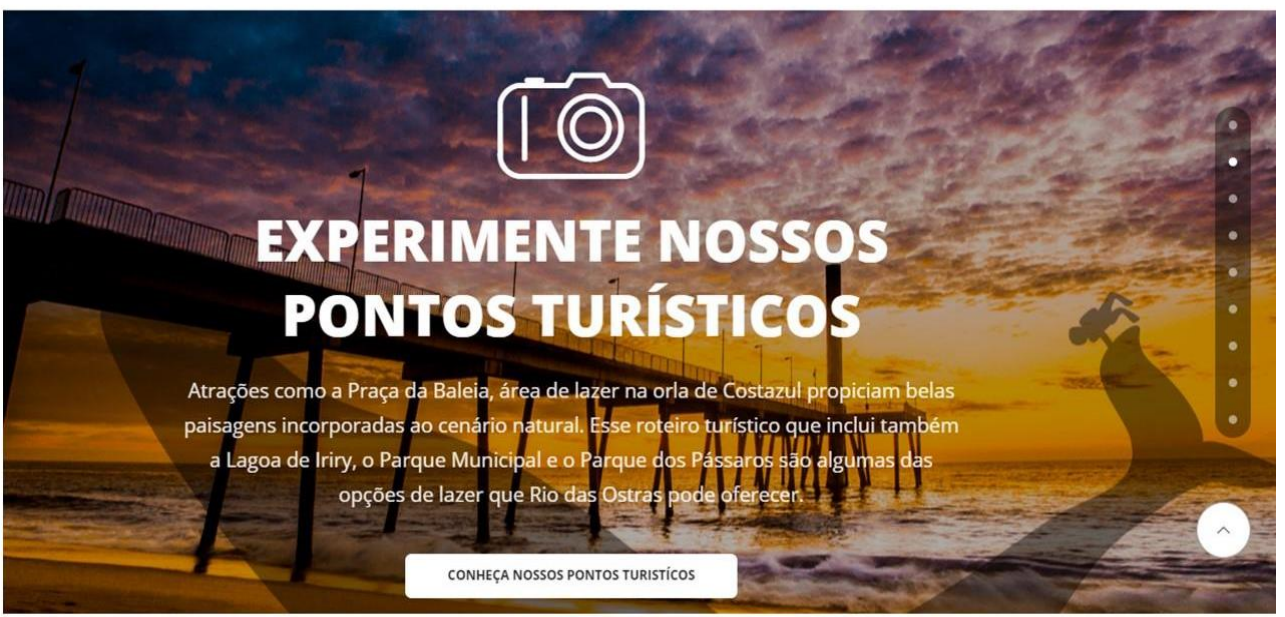

Fonte: Secretaria de Turismo de Rio das Ostras. WebSite. Maio de 2020.

Outros municípios como Cabo Frio (Figura 10), São Sebastião (Figura 11) e llhabela (Figura 12) apresentam publicações muito diretas sobre convites à realização de viagens virtuais atreladas à realidade pandêmica como uma visitação ao Espaço Cultural do Surfe (Cabo Frio).

Figura 10 - Publicação da Secretaria de Turismo de Cabo Frio

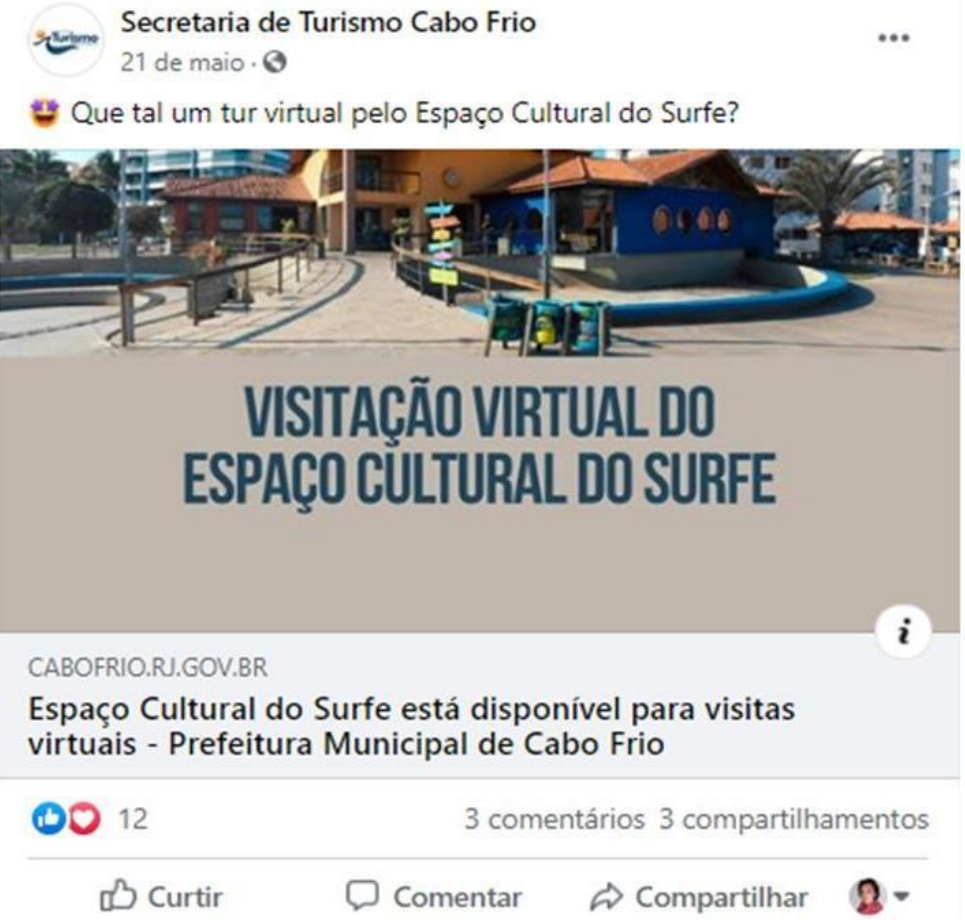

Fonte: Secretaria de Turismo de Cabo Frio. Facebook. Maio de 2020.

Publicações de São Sebastião (Figura 11) e Ilhabela (Figura 12) ilustram um direcionamento mais concentrado na pandemia, respectivamente: "Viaje de casa com a Setur" e "Nossos pensamentos não estão de quarentena, certo? Viaje neles e nos diga: Qual foi o lugar mais incrível que você conheceu em Ilhabela?" 


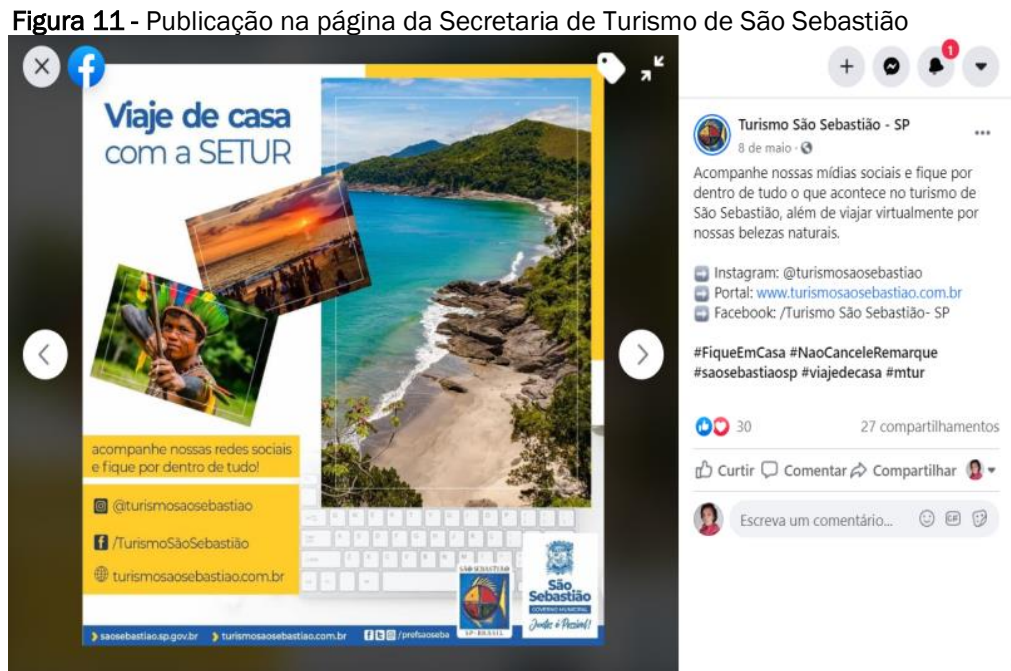

Fonte: Secretaria de Turismo de São Sebastião. Facebook. Maio de 2020

Figura 12 - Publicação da Secretaria de Turismo de Ilhabela

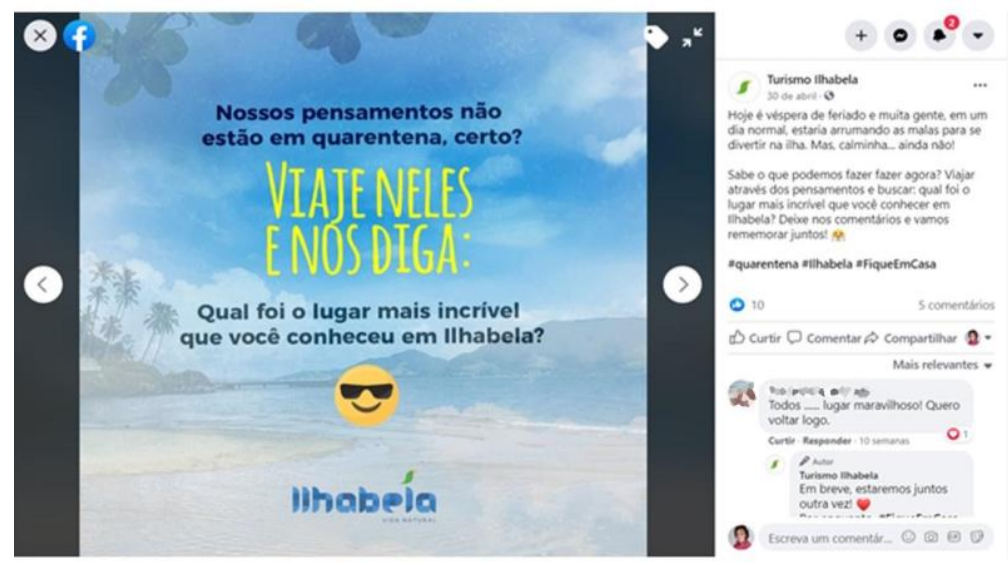

Fonte: Secretaria de Turismo de Ilhabela. Facebook. Abril de 2020.

Muitos municípios se dedicaram à conscientização do turista e do morador. A Secretaria vinculada ao turismo de Armação dos Búzios publicou uma foto com a estátua da Brigitte Bardot usando máscaras, abordagem descontraída que chama atenção pela apropriação de um ícone da cidade (Figura 13).

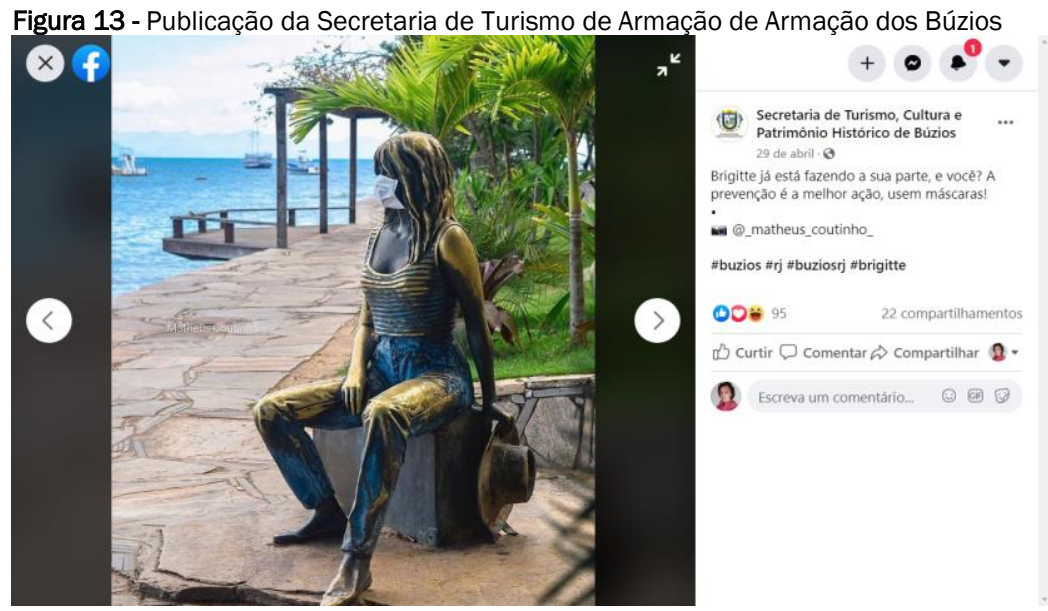

Fonte: Secretaria de Turismo, Cultura e Patrimônio Histórico de Armação dos Búzios.

Facebook. Abril de 2020. 
Alguns municípios foram mais enfáticos nas orientações para conter viagens, como llhabela, São Sebastião e Saquarema. Esses exemplos implicam em alguma contundência simbólica (interrupção de trajetórias) e contrastam certa ternura ao tentar dialogar com visitantes que, agora, não são bem-vindos.

A Secretaria de Turismo de Ilhabela apresenta um ar descontraído sem a presença de imagens de seus atrativos turísticos, mas o contexto de uma casa. Ainda de que forma infantil, o elemento "automóvel" aparece em um diálogo com a prática comum de acesso ao destino - mesmo que num ambiente doméstico (Figura 14).

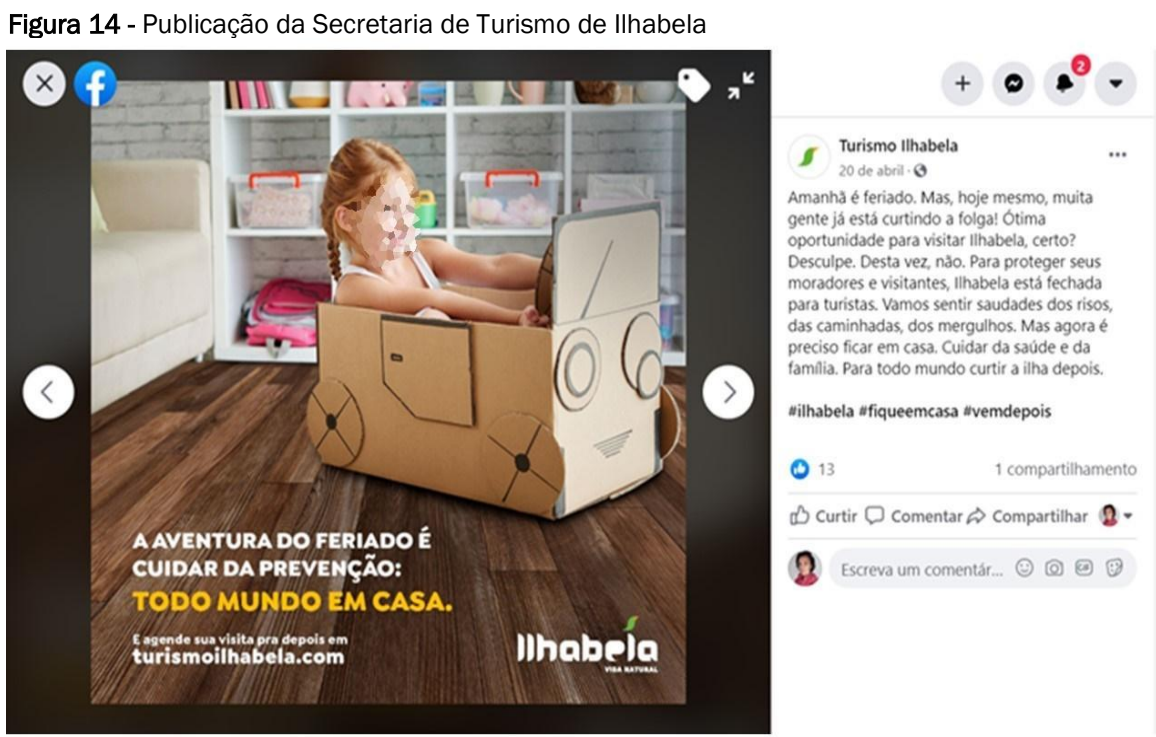

Fonte: Secretaria de Turismo de Ilhabela. Facebook. Abril de 2020.

Com mensagem semelhante, São Sebastião enfatiza a possibilidade de contaminação da população local, argumento fundante para as barreiras sanitárias (Figura 15). 0 destaque está na orientação específica quanto ao feriado, este também incorporado em Saquarema (Figura 16), uma vez que os feriados foram potencializadores para os deslocamentos, levando à (re)instalação das barreiras e, assim, o fomento das comunicações direcionadas aos turistas de modo a contê-los antecipadamente.

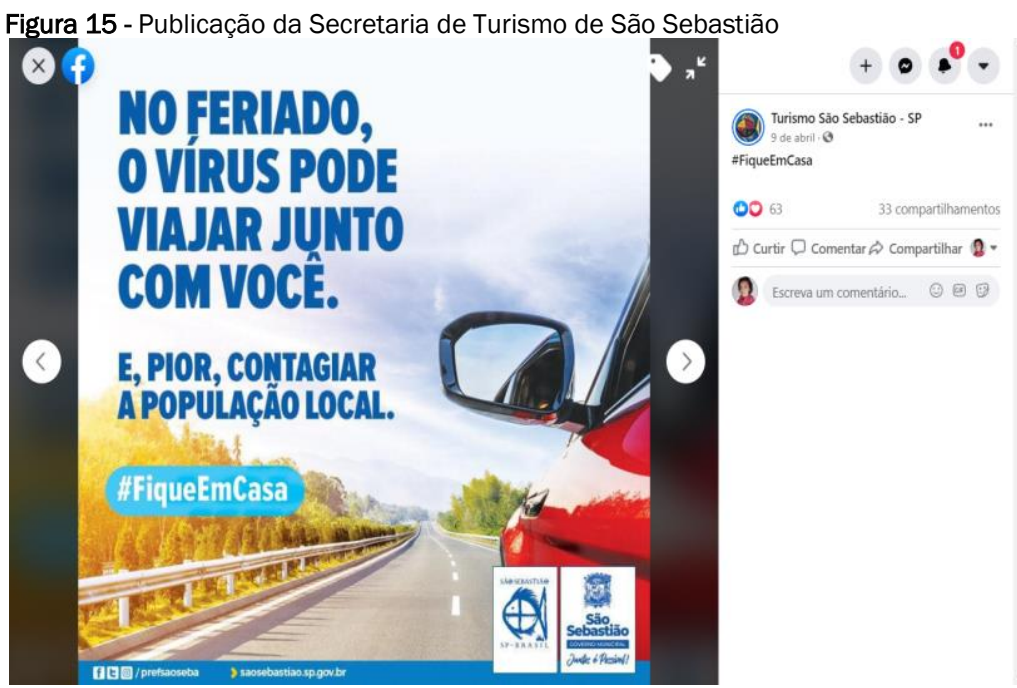

Fonte: Secretaria de Turismo de São Sebastião. Facebook. Abril de 2020

No exemplo trazido na Figura 16, Saquarema é mais direta na mensagem: "Pedimos respeito. Neste feriado respeite a população de Saquarema e não venha para a cidade. Cumpra o isolamento e ajude a prevenir o 
Coronavírus". Ainda assim, indiretamente, promove-se uma paisagem turística da cidade, como imagem de fundo em uma arte gráfica que simula uma mala.

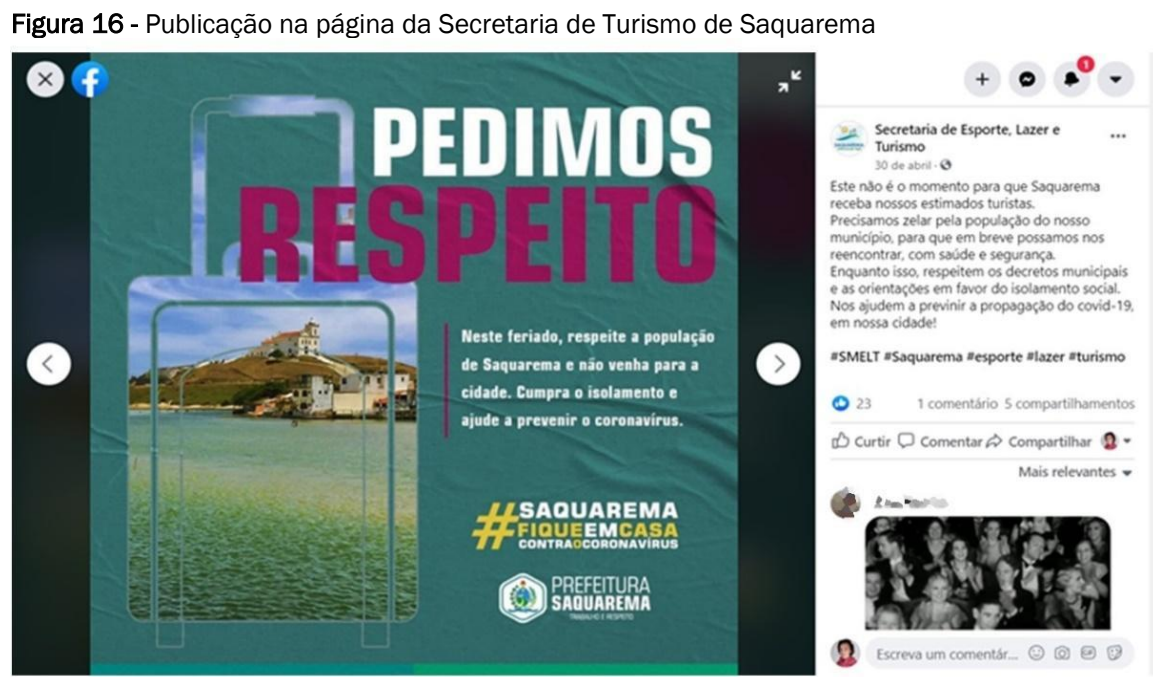

Fonte: Secretaria de Esporte, Lazer e Turismo de Saquarema. Facebook. Abril de 2020.

As comunicações turísticas institucionais sempre tiveram o objetivo de estimular o deslocamento físico para suas localidades, mas na quarentena da COVID-19, o discurso mudou: a orientação é "pare!", "não venha", "viaje depois" - numa ilustração clara de fricções objetivamente impostas aos fluxos tão desejados normalmente. Contudo, tais propagandas estão, em grande parte, atreladas a imagens dos atrativos turísticos dos municípios e a comandos que remetem, implicitamente, à fluidez das viagens turísticas.

A relação dialógica entre as fricções e fluxos do turismo se reflete nas estratégias de comunicação turística, em que a movimentação de diferentes significações e sentidos estão presentes nos/pelos processos comunicacionais, de maneira ordenada/desordenada, conscientes/inconscientes (Baldissera, 2010).

Integrados aos e explorando certos aspectos dos "mobility systems" (Elliott \& Urry, 2010), os municípios vêm utilizando largamente seus canais virtuais para diversas interações on-line durante a pandemia. Com efeito, os papéis dos meios comunicacionais que já vinham se complexificando, na condição de suportes, agora ampliam a centralidade que ocupa no campo das mobilidades turísticas, seja como fontes de informação e de entretenimento, seja com regulação de interações (Aldrigue, 2018).

O estímulo à imobilidade física, verbalizado nas narrações dos vídeos e mensagens escritas dos exemplos apresentados, coexiste com a provocação do próprio destino turístico, através da divulgação em larga escala de fotos de seus atrativos, moradores locais e experiências vividas por seus turistas. 0 caráter inédito da contenção e controle dos fluxos físicos no âmbito global e local oferece uma gama de cenários e oportunidades para o aprofundamento das dimensões imaginativas e virtuais das mobilidades.

No entanto, tais fluxos de informações já aconteciam antes da pandemia - por exemplo, no caso do Museu Interativo do Surf de Cabo Frio, disponível desde 2019. Ainda que esta viagem virtual não tenha sido idealizada em decorrência da pandemia, chama atenção os usos que as localidades vêm estabelecendo de plataformas digitais e recursos online como parte da experiência turística (a distância).

A grande diferença deste momento é que, atreladas a comandos de contenção (fricção), as comunicações incentivam o estímulo às viagens virtuais (fluidez) - com esperança aparente de manter o turismo ativo junto a públicos consumidores, agora forçosamente distanciados dos destinos. Essa aparente contradição é colocada pela manifestação das multi-dimensionalidades das mobilidades turísticas, comprovando que não se trata exclusivamente de deslocamentos físicos.

Em um constante jogo de deslocamento, o movimento de lugares (places in play) foi acentuado, enquanto as fricções impostas pela pandemia interditaram - ou pelo menos, esta foi a tentativa - os locais turísticos (places to play) (Sheller \& Urry, 2004). Fica mais clara a ideia de estilos de vida "geograficamente 
independentes", permitindo assim que mais indivíduos fiquem "livres para viver onde quiserem e viajarem tanto quanto quiserem" (Hannam et al., 2014) - ainda que este "querer" esteja modulado por regras e novas dimensões de co-presença, eminentemente no domínio virtual.

Assim, há uma dimensão das mobilidades turísticas que se mantém durante a pandemia, em espectros temporais e espaciais ampliados. As experiências da multiterritorialidade se exacerbam, sobretudo pela não inédita, mas potencializada - sobreposição espacial simultânea, caracterizada pelas mobilidades virtuais (Haesbaert, 2014) que, neste contexto, possuem relação direta com as ações de comunicação dos destinos turísticos.

De modo geral, ao se valerem imageticamente de ambientes ordinários do cotidiano (especialmente, Saquarema e São Sebastião), as comunicações transparecem um aparente cuidado com a população local, dada a necessidade de se fecharem para cuidar dos moradores. Ao compreender que o olhar turístico acontece de forma cada vez menos específica, extrapola-se a delimitação de espaços/tempos ordinários e extraordinários (Allis, 2016): por um lado, uma mensagem de altruísmo (por parte dos governantes) e também de familiaridade, até porque provavelmente boa parte dos visitantes destes lugares são veranistas de segunda residência. Por outro, ao veicular imagens com intenso apelo turístico, recorre-se a estéticas de comunicação clássicas: "produzir imagens com os turistas na imagem, [possibilita] ao leitor imaginar-se fisicamente na paisagem. Tais imagens guiam as fantasias do leitor e as fazem parecer realizáveis: isso poderia ser eu!" (Larsen, 2002, p. 35).

Uma aproximação óbvia que se poderia fazer entre comunicação e turismo talvez fossem as tentativas de estimular alguma forma de turismo virtual, em substituição a um turismo in situ, prática impossível, proibida ou não recomendável neste momento. Contudo, conforme os conceitos de mobilidades turísticas indicam, é necessário desviar de abordagens do turismo de maneira unidimensional. Há, aqui, uma tentativa geral dos municípios em manter um diálogo (através do fluxo constante de mensagens e imagens pelas redes virtuais) com os visitantes, que estão impedidos de entrar nas cidades. Diálogo que se espera converter novamente em prática turística presencial, em um futuro que, apesar de prometido, não se pode precisar em que momento ocorrerá.

\section{CONCLUSÃO}

Este trabalho deu destaque para as mobilidades que vão além do deslocamento físico, demonstrando que (i)mobilidades turísticas (como conceito e prática) não se restringem às viagens de corpos de turistas. Em realidade, o turismo engloba também diversas mobilidades imaginativas, que foram mais evidenciadas no contexto pandêmico. Contudo, não há somente dicotomias e contradições, mas também cruzamentos e transversalidade quando se trata das mobilidades turísticas. Medidas de governos locais para o fechamento de limites municipais e limitação da circulação são recorrentes e afetam o deslocamento de pessoas e objetos, assim como o turismo. No entanto, as restrições de acesso e controle nos limites municipais são respostas diretas à insistência de acesso de pessoas de fora das localidades durante a pandemia - o que seria um contrassenso em que pese a urgência de se controlar a dispersão do vírus.

As tentativas de entrada de não residentes, geralmente para usufruir de segunda residência ou casas alugadas, se destacaram nessa trama. Um caráter fluido de identidades buscava ser acionado para, em situações convenientes, garantir os privilégios da mobilidade, quando o contexto impõe o controle de circulações. Assim, esse benefício (circular de carro, mesmo quando as fricções impostas indicam o caráter indesejado da visita) é exercido de maneira perigosa: corpos em movimento aos destinos turísticos podem ser vetores de propagação da COVID-19, de maneira que os agentes locais (poder público ou comunidades), que em situações normais anseiam pelas visitas turísticas, agora se conjugam para regular estes regimes de mobilidade através de contenção física e rechaço a esses fluxos.

Por outro lado, os agentes públicos e privados buscaram antever o retorno próximo do turismo póspandemia: mesmo com mensagens de afastamento, os esquemas de comunicação seguiram alimentando uma cultura de viagens no campo imagético. Pessoas se movimentam e percorrem locais que um dia juram visitar "quando tudo isso acabar". Mobilidades imaginativas estimuladas através de imagens que retratam o destino turístico que, embora, agora desritmado, ainda circula pelo imaginário dos potenciais visitantes. 
Assim, dificilmente se poderia dizer que o turismo parou - a despeito das barreiras e controles nos acessos aos municípios. Ironicamente, este turismo segue ativo, ainda que apenas nos imaginários e por deslocamentos de um pequeno grupo privilegiado - que, em geral, burla regras de acesso aos destinos. Este regime de mobilidades turísticas, portanto, escancara poderes assimétricos de acesso, fruição e produção do espaço.

Não havia uma intenção de estabelecer relação causal entre os fluxos dos "turistas da pandemia" e as imagens e mensagens veiculadas, muito porque os sujeitos são também construtores e construções do/no processo comunicacional, não sendo somente polos passivos. No entanto, a instigante convergência dessas dimensões de mobilidades reforça a urgência de nova problematização sobre o fazer turístico durante a pandemia, que continua acontecendo - seja na persistência (por parte de viajantes) destes fluxos, seja na incessante circulação de imagens de natureza claramente turística, ainda que contendo comandos de controle.

Este trabalho não somente trata de questões que acontecem durante a pandemia, mas também é escrito enquanto esta se desenrola. Por isso, é um trabalho datado. As percepções, análises e conclusões são influenciadas pelas respostas e reações que acadêmicos, agente privados e gestores de turísticos vêm manifestando. Assim, reconhecemos que, na sua vertente empírica, a escolha das comunicações (selecionadas intencionalmente, ainda que com alguma abrangência) e a atenção aos primeiros decretos municipais para o enfrentamento da pandemia (em geral, entre março e abril de 2020) podem ter limitado alguns aspectos da análise proposta. Ainda assim, recuperamos uma das intenções do trabalho, que julgamos ter atingido: compreender parte da realidade do turismo durante a pandemia da COVID-19, valendo-se das mobilidades turísticas como categoria de análise central.

De fato, a contraposição e conjugação de mobilidades-imobilidades em suas várias dimensões proporcionaram elementos oportunos para a compreensão do contexto e para avançar em uma elaboração teórica em processo - que extrapola os fenômenos observados durante a pandemia. Portanto, tal janela de reflexões que a pandemia abre, permite colocar a episteme do próprio turismo em movimento. Perceber isso representa um exercício detalhado e intencionado de posicionar o turismo no centro do debate das mobilidades, na perspectiva deste giro epistêmico apresentado.

Em meio a uma profusão de estudos sobre turismo pós-pandemia, sem negligenciar a necessidade de desenhar cenários futuros, é essencial entender com responsabilidade o desenrolar dos efeitos da pandemia (e de qualquer outra crise) no presente, sob o risco de o futuro ser um espaço-tempo demasiadamente abstrato, apriorístico e, ainda pior, descolado de realidades emergentes no processo.

Assim, mobilidades (mais) justas precisariam ser pensadas nas escalas corporal, da rua, urbana ampliada, nacional e planetária. Este é, de fato, o compromisso subjacente deste (não tão) novo paradigma das mobilidades. Por isso a relevância - ainda durante uma pandemia - de pensar as múltiplas representações de turismo e não apenas urgir sua retomada em um futuro que pouco se conhece. As mobilidades turísticas - especialmente no contexto da pandemia - podem informar muito sobre um intrincado regime de mobilidades, que são essencialmente desiguais.

Além de estudos que considerem outras localidades do Brasil e do mundo, com este trabalho desvelam-se outras agendas para trabalhos futuros que poderiam se desdobrar a partir deste - especialmente se optarem por sustentar as análises de problemas concretos no arcabouço das mobilidades turísticas: estudos no campo da comunicação e marketing (semiótica, realidade virtual/aumentada, interação humano-máquina, processos decisórios de compra e avaliação de qualidade), direito constitucional e administrativo, planejamento e gestão de destinos (em face de novas dinâmicas turísticas), estudos comunitários (identidade, impactos socioculturais), saúde pública e coletiva (aspectos sanitários e epidemiológicos).

\section{REFERÊNCIAS}

Aguiar, S. (2020). COVID-19: A doença dos espaços de fluxos. Geographia, 22(48), p. 51-74. https://doi.org/10.22409/GEOgraphia2020.v22i48.a42848

Aldrigue, N. S. (2018). O turismo para a comunicação ou a comunicação para o turismo? Quem consome quem? CENÁRIO, 6(10), p. 72-84. https://doi.org/10.26512/revistacenario.v6i10.18761 
Allis, T. (2016). Em busca das mobilidades turísticas. Plural, 23(2), p. 94-117.

https://doi.org/10.11606/issn.2176-8099.pcso.2016.125112

Alves, F. G., Costa, H. S. \& Perinotto, A. R. C. (2017). Instagram como ferramenta para fidelização de clientes: Fotografia, Redes Sociais e Turismo. Marketing \& Tourism Review, 2(2), dez.

Baba, C., Stăncioiu, A.-F., Gabor, M. R., Alexe, F.-A., Oltean, F. D., \& Dinu, A. C. (2020). Considerations regarding the effects of COVID-19 on the tourism market. Theoretical and Applied Economics, XXVII(3), p. 271284.

Bajardi, P., Poletto, C., Ramasco, J. J., Tizzoni, M., Colizza, V., \& Vespignani, A. (2011). Human mobility networks, travel restrictions, and the global spread of 2009 H1N1 pandemic. PLOS ONE, 6(1). https://doi.org/10.1371/journal.pone.0016591

Baldissera, R. (2010). Comunicação Turística. Rosa dos Ventos, 1(1), p. 6-15.

Baptista, M. R. C. (2014). Cartografia de Saberes na Pesquisa em Turismo: Proposições Metodológicas para uma Ciência em Mutação. Revista Rosa dos Ventos, 6(3), p. 342-355.

Baum, T., \& Hai, N. T. T. (2020). Hospitality, tourism, human rights and the impact of COVID-19. International Journal of Contemporary Hospitality Management, 32(7), p. 2397 - 2407. https://doi.org/10.1108/IJCHM-03-2020-0242

Belik, V., Geisel, T., \& Brockmann, D. (2011). Natural Human Mobility Patterns and Spatial Spread of Infectious Diseases. Physical Review X, 1(1), p. 1-5.

Chang, C.-L., McAleer, M., \& Ramos, V. (2020). A charter for sustainable tourism after COVID-19. Sustainability, 12(9), p. 1-4. https://doi.org/10.3390/su12093671

Cresswell, T. (2006). On the move: mobility in the modern western world. Routledge.

Cresswell, T. (2010). Towards a Politics of Mobility. Environment and Planning D: Society and Space, 28. https://doi.org/10.1068/d11407

Depoux, A., Martin, S., Karafillakis, E., Preet, R., Wilder-Smith, A., \& Larson, H. (2020). The pandemic of social media panic travels faster than the COVID-19 outbreak. Journal of Travel Medicine, 27(3). https://doi.org/10.1093/itm/taaa031

Elliott, A., \& Urry, J. (2010). Mobile Lives. Routledge.

Epstein, J. M., Goedecke, D. M., Yu, F., Morris, R. J., Wagener, D. K., \& Bobashev, G. V. (2007). Controlling pandemic flu: The value of international air travel restrictions. PLOS ONE, 2(5). https://doi.org/10.1371/journal.pone.0000401

Ferrari, C. M. M. \& Gandara, J.M. (2015). Fotografias de viagens: replicando cenas da viagem perfeita em Curitiba/PR. Caderno Virtual de Turismo, 15(2), p. 112-130, ago.

Freire-Medeiros, B., Telles, V., \& Allis, T. (2018). Por uma teoria social on the move. Tempo Social, 30(2). https://doi.org/10.11606/0103-2070.ts.2018.142654

Gössling, S., Scott, D., \& Hall, C. M. (2020). Pandemics, tourism and global change: a rapid assessment of COVID-19. Journal of Sustainable Tourism, O(0), p. 1-20. https://doi.org/10.1080/09669582.2020.1758708

Haesbaert, R. (2014). Viver no limite: território e multi/transterritorialidade em tempos de insegurança e contenção. Bertrand.

Haesbaert, R. (2020). Reflexões geográficas em tempos de pandemia. Espaço e Economia, 18. https://doi.org/10.4000/espacoeconomia.11826

Hall, M. (2011). Biosecurity, tourism and mobility: Institutional arrangements for managing tourism-related biological invasions. Journal of Policy Research in Tourism, Leisure and Events, 3(3), p. 256-280. https://doi.org/10.1080/19407963.2011.576868

Hall, M., Scott, D., \& Gössling, S. (2020). Pandemics, transformations and tourism: be careful what you wish for. Tourism Geographies, 22(3), p. 577-598. https://doi.org/10.1080/14616688.2020.1759131

Hannam K., Sheller M., \& Urry, J. (2006). Editorial: Mobilities, Immobilities and Moorings. Mobilities, 1. https://doi.org/10.1080/17450100500489189

Hannam, K., Butler, G., \& Paris, C. M. (2014). Developments and key issues in tourism mobilities. Annals of Tourism Research, 44(1). https://doi.org/10.1016/i.annals.2013.09.010 
Haywood, K. M. (2020). A post COVID-19 future - tourism re-imagined and re-enabled. Tourism Geographies, 22(3), p. 599-609. https://doi.org/10.1080/14616688.2020.1762120

Higgins-Desbiolles, F. (2020a): Socialising tourism for social and ecological justice after COVID-19, Tourism Geographies, https://doi.org/10.1080/14616688.2020.1757748

Higgins-Desbiolles, F. (2020b). The "war over tourism": challenges to sustainable tourism in the tourism academy after COVID-19. Journal of Sustainable Tourism, p. 1-19. https://doi.org/10.1080/09669582.2020.1803334

lacus, S. M., Natale, F., Santamaria, C., Spyratos, S., \& Vespe, M. (2020). Estimating and projecting air passenger traffic during the COVID-19 coronavirus outbreak and its socio-economic impact. Safety Science, 129. https://doi.org/10.1016/j.ssci.2020.104791

laquinto, B. L. (2020). Tourist as vector: Viral mobilities of COVID-19. Dialogues in Human Geography, 10(2). https://doi.org/10.1177/2043820620934250

Ioannides, D., \& Gyimóthy, S. (2020). The COVID-19 crisis as an opportunity for escaping the unsustainable global tourism path. Tourism Geographies, May. https://doi.org/10.1080/14616688.2020.1763445

Jamal, T. \& Budke, C. (2020). Tourism in a world with pandemics: local-global responsibility and action. Journal of Tourism Futures, 6(2), p. 181-188. https://doi.org/10.1108/JTF-02-2020-0014

Kaufman, V. (2010). Re-Thinking Mobility: Contemporary Sociology. Ashgate.

Kunz, J. G. (2015). As Mobilidades Turísticas como Objeto de Pesquisa: Um Panorama dos Periódicos Estrangeiros. Rosa Dos Ventos, 7(3), p. 377-391.

Larsen, J. (2002). (Dis)Connecting Tourism and Photography: Corporeal Travel and Imaginative Travel Early photography. Journeys, 5(2). https://doi.org/10.3167/jys.2004.050202

Martin, G., \& Boland, M. (2018). Planning and preparing for public health threats at airports. Globalization and Health, 14(28). https://doi.org/10.1186/s12992-018-0323-3

Mello, C. (2004). Extremidades do vídeo: o vídeo na cultura digital. Conexão - Comunicação e Cultura, 3(6).

Mello, C. M. (2015). O modelo semiótico de análise e leitura sensorial de fotografias turísticas. Revista Hospitalidade, 12(1), jun.

Meloni, S., Perra, N., Arenas, A., Gómez, S., Moreno, Y., \& Vespignani, A. (2011). Modeling human mobility responses to the large-scale spreading of infectious diseases. Scientific Reports, 1(62), p. 1-7. https://doi.org/10.1038/srep00062

Merler, S., Ajelli, M., Pugliese, A., \& Ferguson, N. M. (2011). Determinants of the spatiotemporal dynamics of the 2009 H1N1 pandemic in Europe: Implications for real-time modelling. PLoS Computational Biology, 7(9). https://doi.org/10.1371/journal.pcbi.1002205

Ministério do Turismo. (2019). 30 Rotas Turísticas Estratégicas. Recuperado de http://www.turismo.gov.br/images/InvesteTurismo/Rotas Turísticas Estratégicas-InvesteTurismo.pdf

Mostafanezhad, M., Cheer, J. M., \& Sin, H. L. (2020). Geopolitical anxieties of tourism: (Im)mobilities of the COVID-19 pandemic. Dialogues in Human Geography, 10(2), p. 182-186.

https://doi.org/10.1177/2043820620934206

Oliveira Neto, T., Garcia, T. de S. L., \& Spinussi, E. (2020). Pandemia de COVID-19, as fronteiras pelo mundo e o transporte aéreo na Itália. Confins, 44. https://doi.org/10.4000/confins.27577

Renaud, L. (2020). Reconsidering global mobility-distancing from mass cruise tourism in the aftermath of COVID-19. Tourism Geographies, p. 679-689. https://doi.org/10.1080/14616688.2020.1762116

Sánchez, M. M. (2020). Flujos turísticos, geopolítica y COVID-19: cuando los turistas internacionales son vectores de transmisión. Geopolítica(s). Revista de Estudios Sobre Espacio y Poder, 11(Especial). https://doi.org/10.5209/geop.69249

Seabra, A. L. de C. (2017). A competitividade entre destinos na era digital: Uma análise do potencial das mídias sociais no incremento da atratividade turística do destino Portugal. Turismo \& Sociedade, 10(3), 125, set-dez. http://dx.doi.org/10.5380/tes.v10i3.54966

Sheller, M. (2014). Sociology after the Mobilities Turn. In P. Adey, D. Bissel, K. Hannam \& M Sheller (Eds.). The Routledge Handbook of Mobilities. Routledge. 
Sheller, M. (2018a). Mobility justice: the politics of movement in an age of extremes. Verso.

Sheller, M. (2018b). Theorizing mobility justice. Tempo Social, 30(2). https://doi.org/10.11606/01032070.ts.2018.142763

Sheller, M. (2020). Reconstructing tourism in the Caribbean: connecting pandemic recovery, climate resilience and sustainable tourism through mobility justice. Journal of Sustainable Tourism, p. 1-14. https://doi.org/10.1080/09669582.2020.1791141

Sheller, M., \& Urry, J. (2004). Tourism Mobilities: places to play, place in play. Routledge.

Sheller, M., \& Urry, J. (2006). The new mobilities' paradigm. Environment and Planning A: Economy and Space. 38(2). https://doi.org/10.1068/a37268

Shi, Q., Dorling, D., Cao, G., \& Liu, T. (2020). Changes in population movement make COVID-19 spread differently from SARS. Social Science and Medicine, 255(May). https://doi.org/10.1016/j.socscimed.2020.113036

Silva, S.K.M. \& Alves, M.L.B. (2014). Fotografias da "Cidade do Sol": um registro de revelações e ocultações. Revista Brasileira de Pesquisa em Turismo, 8(3), p. 456-475, set./dez. https://doi.org/10.7784/rbtur.v8i3.807

Tremblay-Huet, S. (2020). COVID-19 leads to a new context for the "right to tourism": a reset of tourists' perspectives on space appropriation is needed. Tourism Geographies, 22(3). https://doi.org/10.1080/14616688.2020.1759136

Trigo, L. G. G. (2020). Viagens e turismo: dos cenários imaginados às realidades disruptivas. Revista Brasileira de Pesquisa em Turismo, 14(3), p. 1-13. https://doi.org/10.7784/rbtur.v14i3.2107

Urry, J. (2000). Sociology Beyond Societies: Mobilities for the Twenty-First Century. Routledge.

World Health Organization [WHO]. (2020, march 11). WHO Director-General's opening remarks at the media briefing on COVID-19 - 2020. Recuperado de https://www.who.int/dg/speeches/detail/who-directorgeneral-s-opening-remarks-at-the-media-briefing-on-covid-19---11-march-2020

World Tourism Organization [UNWTO]. (2020, april 28). COVID-19 related travel restrictions a global review for tourism. Second report. Recuperado de https://webunwto.s3.eu-west-1.amazonaws.com/s3fs-public/2020-04/TravelRestrictions\%20-\%2028\%20April.pdf

Yu, M., Li, Z., Yu, Z., He, J., \& Zhou, J. (2020). Communication related health crisis on social media: a case of COVID-19 outbreak. Current Issues in Tourism, April. https://doi.org/10.1080/13683500.2020.1752632

Zheng, Y., Goh, E., \& Wen, J. (2020). The effects of misleading media reports about COVID-19 on Chinese tourists' mental health: a perspective article. Anatolia, 31(2).

https://doi.org/10.1080/13032917.2020.1747208

\section{ON-LINE REFERENCES}

Cristine, M. (2020, March 17). Pescadores bloqueiam desembarque de barca em Ilha Grande, após decreto devido ao coronavírus. Extra. Saúde e Ciência. Recuperado 17 Maio 2020, de https://extra.globo.com/noticias/saude-e-ciencia/pescadores-bloqueiam-desembarque-de-barca-em-ilha-grandeapos-decree-devido-ao-coronavirus-rv1-1-24309995.html

Folha dos Lagos. (2020, April 14). Quase 30\% dos veículos são barrados nas barreiras sanitárias em Cabo Frio. Recuperado 14 apr. 2020, de https://www.folhadoslagos.com/geral/quase-30-dos-veiculos-sao-barrados-nas-barreiras-sanitarias-em-cabo/13030/

G1. Santa Catarina. (2020, May 21). Balneário Camboriú, São Joaquim e outras cidades montam barreiras sanitárias por causa da pandemia. Recuperado 21 Maio 2020, de https://g1.globo.com/sc/santa-catarina/noticia/2020/05/21/balneario-camboriu-sao-joaquim-e-outras-cidades-montam-barreiras-sanitariaspor-causa-da-pandemia.ghtml

Garcia, D. (2020, May 16). Mesmo com balsa restrita, Ilhabela enfrenta multiplicação de casos de coronavírus. Folha de São Paulo. Recuperado 16 Maio 2020, de https://www1.folha.uol.com.br/cotidiano/2020/05/mesmo-com-balsa-fechada-ilhabela-enfrenta-multiplicacao-de-casos-de-coronavirus.shtml 
Gonçalves, E. \& Siqueira, A. (2020, May 19). Feriadão em SP preocupa prefeitos de locais turísticos: 'Tremendo absurdo'. Veja. Recuperado 19 Maio 2020, de https://veja.April.com.br/brasil/feriadao-em-sp-preocupa-prefeitos-de-locais-turisticos-tremendo-absurdo/

Ilhabela. (2020, mar 24). Ilhabela ate daqui a pouco - fique em casa. Recuperado 24 mar. 2020, de https://www.youtube.com/watch?v=1CJ7Y5LmUHE\&feature=youtu.be

O São Gonçalo. (2020, junho 2). Búzios continua com as barreiras sanitárias. Recuperado 02 jun. 2020, de https://www.osaogoncalo.com.br/regiao-dos-lagos/83574/buzios-continua-com-as-barreiras-sanitarias

Passa Palavra. Paraty. (2020, jun 14). Como fazer uma barreira sanitária no seu bairro? Recuperado 14 jun. 2020, de https://passapalavra.info/2020/06/132546/

Prefeitura de Arraial do Cabo. (2020, junho 10). [Instagram] Recuperado 10 jun. 2020, de https://www.instagram.com/p/CBgDZaVlo8t/

Tomazela, J. M. (2020, julho 3). Cidades do Interior fecham tudo em fim de semana para evitar o turista de chácara. O Estado de S. Paulo. Recuperado 3 Jul. 2020, de https://sao-paulo.estadao.com.br/noticias/geral,cidades-do-interior-fecham-tudo-em-fim-de-semana-para-evitar-turista-de-chacara,70003353292

Tomazela, J. M. (2020, May 21). Isolamento em cidades do litoral de SP cai com 'megaferiado' na capital. UOL. Recuperado 21 Maio 2020, de https://noticias.uol.com.br/ultimas-noticias/agencia-estado/2020/05/21/litoral-paulista-rejeita-turistas-isolamento-cai.htm?cmpid=

UOL, Coronavírus. (2020, agosto 13). Justiça derruba decrees que restringiam entrada em Ilhabela na pandemia. Recuperado 13 Ago. 2020, de https://noticias.uol.com.br/ultimas-noticias/agencia-estado/2020/07/04/justica-derruba-decrees-que-restringiam-entrada-em-ilhabela-na-pandemia.htm

Vai Paraty. (2020, junho 25). Associação de Moradores faz pesquisa e $63 \%$ dos moradores decidem pela continuação da barreira na entrada. Só entra morador! Recuperado 25 Jun. 2020, de https://vaiparaty.com.br/associacao-de-moradores-faz-pesquisa-e-63-dos-moradores-decidem-pela-continuacao-da-barreira-na-entrada-so-entra-morador/

Veja. (2020, April 11). Moradores hostilizam turistas que descumprem quarentena em praia de SP. Recuperado 11 apr. 2020, de https://veja.April.com.br/brasil/moradores-hostilizam-turistas-que-foram-a-praiade-barra-do-sahy/.

\section{Informações dos autores}

\section{Juliana Carneiro}

Mestre em Turismo pelo Programa de Pós Graduação Stricto Sensu em Turismo UFF. Especialista em Docência do Ensino Superior. Bacharel em Turismo pela Faculdade de Turismo e Hotelaria da UFF. É pesquisadora do grupo de pesquisa da UFF Turismo, Gestão e Território. É mediadora a distância do Consórcio CEDERJ vinculado a UFRRJ e Assistente Editorial da revista acadêmica Caderno Virtual de Turismo (CVT).

Contribuições para o trabalho: concepção da pesquisa, revisão da literatura, coleta de dados, análise de dados e discussão, versão do texto para a Língua Inglesa.

E-mail: julianacarneiro@id.uff.br

ORCID: https://orcid.org/0000-0002-5986-1556

\section{Thiago Allis}

Bacharel em Turismo pela Universidade de São Paulo (2004), Mestre em Integração da América Latina pela Universidade de São Paulo (2006) e Doutor em Arquitetura e Urbanismo, na Área de Planejamento Urbano e Regional (FAUUSP), com interesse nos assuntos ligados ao turismo, ao planejamento do turismo, ao turismo urbano e às mobilidades. Atualmente é Professor Doutor pelo Curso de Lazer e Turismo, da Escola de Artes Ciências e Humanidades, da Universidade de São Paulo (EACH-USP). Tem experiência profissional na área de Planejamento Turístico, tendo prestado consultorias e serviços técnicos especializados para entidades de governo e empresas privadas. Em 2012, foi Professor Visitante na Universidade Nacional Timor Lorosa'e (Timor Leste), junto ao Departamento de Comércio e Turismo.

Contribuições para o trabalho: concepção da pesquisa, revisão da literatura, coleta de dados, análise de dados e discussão, versão do texto para a Língua Inglesa.

E-mail: thiagoallis@usp.br

ORCID: http://orcid.org/0000-0002-9070-7928 